\title{
The role of quercetin in plants
}

\author{
Priyanka Singh ${ }^{1}$, Yamshi Arif ${ }^{1}$, Andrzej Bajguz ${ }^{2}$, and Shamsul Hayat ${ }^{1}$ \\ ${ }^{1}$ Aligarh Muslim University Faculty of Life Sciences \\ ${ }^{2}$ University of Bialystok
}

February 11, 2021

\begin{abstract}
Flavonoids are a special category of hydroxylated phenolic compounds having an aromatic ring structure. Quercetin is a special subclass of flavonoid. It is a bioactive natural compound built upon the flavon structure nC6(ring A)-C3(ring C)-C6(ring B). Quercetin facilitates several plant physiological processes, such as seed germination, pollen growth, antioxidant machinery, and photosynthesis, as well as induces proper plant growth and development. Quercetin is a powerful antioxidant, so it potently provides plant tolerance against several biotic and abiotic stresses. This review highlights quercetin's role in increasing several physiological and biochemical processes in under stress and non-stress environments. Additionally, this review briefly assesses quercetin's role in mitigating biotic and abiotic stresses (e.g., salt, heavy metal, and UV stress). The biosynthesis of flavonoids, their signaling pathways, and quercetin's role in plant signaling are also discussed.
\end{abstract}

\section{The role of quercetin in plants}

Priyanka Singh ${ }^{1}$, Yamshi Arif ${ }^{1}$, Andrzej Bajguz ${ }^{2}$ and Shamsul Hayat ${ }^{1 *}$

${ }^{1}$ Department of Botany, Plant Physiology Section, Faculty of Life Sciences, Aligarh Muslim University, Aligarh 202002, India

${ }^{2}$ Department of Biology and Plant Ecology, Faculty of Biology, University of Bialystok, 1J Ciolkowskiego St., 15-245 Bialystok, Poland

${ }^{*}$ Corresponding author:

email: hayat_68@yahoo.co.in

Phone number: +919412328593

ORCID ID: 0000-0002-2476-5409

\section{Abstract}

Flavonoids are a special category of hydroxylated phenolic compounds having an aromatic ring structure. Quercetin is a special subclass of flavonoid. It is a bioactive natural compound built upon the flavon structure nC6(ring A)-C3(ring C)-C6(ring B). Quercetin facilitates several plant physiological processes, such as seed germination, pollen growth, antioxidant machinery, and photosynthesis, as well as induces proper plant growth and development. Quercetin is a powerful antioxidant, so it potently provides plant tolerance against several biotic and abiotic stresses. This review highlights quercetin's role in increasing several physiological and biochemical processes in under stress and non-stress environments. Additionally, this review briefly assesses quercetin's role in mitigating biotic and abiotic stresses (e.g., salt, heavy metal, and UV stress). The biosynthesis of flavonoids, their signaling pathways, and quercetin's role in plant signaling are also discussed. 
Keywords: biosynthesis, chalcone, flavonoids, phytohormones, secondary metabolites

\section{Introduction}

Plants produce huge amounts of different primary and secondary metabolites. Primary metabolites are directly involved in photosynthesis; energy expenditure process; fat, protein, and carbohydrate metabolisms; and the vital activities of cells. Primary metabolites are used up by plant cells, while secondary metabolites perform several activities in different parts of the plant, either in situ or ex situ. The synthesis of secondary metabolites is restricted by its location, as every organ has a different need for secondary metabolites. Light, ultraviolet radiations, drought, salinity, and numerous other sorts of stresses also modulate the production of secondary metabolites (Yanqun Li, Kong, Fu, Sussman, \& Wu, 2020; Nabavi et al., 2020).

Shikimic acid and glycolytic pathways are the initial steps for secondary metabolite synthesis. The subsequent variations, including the involvement of different enzymes and cell type, are responsible for synthesizing diverse kinds of secondary metabolites (Yanqun Li et al., 2020). Several extrinsic factors also modify the biosynthesis of these metabolites. Developmental factors alter the initiation and differentiation of plant parts responsible for secondary metabolites synthesis and storage. On the other hand, various extrinsic factors also regulate these processes. Sanchita (2018) observed that fluctuating environments greatly influence the gene responsible for secondary metabolites biosynthesis, so these metabolites' quantity and quality get modified. According to their synthesizing pathway, as many as 100,000 secondary metabolites are present in different plant species. They were categorized into three distinct categories, i.e., terpenes (isoprenoids), nitrogencontaining compounds (i.e., alkaloids, cyanogenic glycosides, and glucosinolates), and phenolic compounds (i.e., phenylpropanoids and flavonoids) (Fang et al., 2016).

Among several secondary metabolites, flavonoids are broadly recognized as compounds carrying an aromatic ring with a minimum single hydroxyl group. Around 8000 phenolic compounds have been identified so far from various plants, half of which are flavonoids found as glycosides, aglycone, and methylated derivatives. The synthesis of flavonoids is done via the polypropanoid pathway, where phenylalanine acts as a startup molecule. Flavonoids, which were initially named vitamin $\mathrm{P}$, in combination with vitamin $\mathrm{C}$, were reported as valuable for maintaining the integrity of the capillary wall and capillary resistance (Havsteen, 1983). The nature of flavonoids depends on their degree of hydroxylation and polymerization, structural class, other conjugations, and substitutions (Ahmed et al., 2016; Kumar \& Pandey, 2013). Flavonoids are classified into several subclasses comprising flavonols (e.g., quercetin, myricetin, fisetin, and kaempferol), flavones (e.g., apigenin, luteolin, and flavones), isoflavonoids, flavanones (e.g., naringenin, flavanone, and hesperetin), isoflavones, catechins, and anthocyanidins. The free radicals scavenging property of flavonoids, is considered in medicine (Cook \& Samman, 1996; Van Acker et al., 1996).

This review highlights quercetin's role in plants, and its biosynthesis and regulation. It also focuses on the role of quercetin in signal transduction, as well as its potential role in providing plant stress tolerance by modulating diverse physio-biochemical traits.

\section{Occurrence}

Quercetin, a plant pigment widely present in tea and onion, works as an antioxidant. The name quercetin derives from the Latin wordquercetum, which means Quercus robur (oak). Quercetin has medical properties, including anti-allergy, anti-inflammatory, anti-cancer, cardiovascular protection, anti-tumor, antiviral, anti-diabetic, immunomodulatory, anti-hypertensive, and gastroprotective effects (Lakhanpal \& Rai, 2007). Quercetin is yellow-colored, a crystalline insoluble solid substance having a bitter taste. Despite its general insolubility, it is slightly soluble in alcohol, aqueous alkaline solutions, and glacial acetic acid. The fluctuation in photosynthetic photon flux density $\left(43-230 \mu \mathrm{mol} \mathrm{m} \mathrm{m}^{-2} \mathrm{~s}^{-1}\right)$ regulates the quercetin content in plants (Becker, Klaering, Schreiner, Kroh, \& Krumbein, 2014). Plants sources of quercetin include Morus alba (Moraceae),Camellia sinensis (Theaceae), Calamus scipionum(Calamoidaceae), Allium fistulosum (Amaryllidaceae), Centella asiatica (Apiaceae), Moringa oleifera (Moringa),Hypericum perforatum (Hyperiaceae), Hypericum hiricinum(Clusiaceae), Nasturtium officinale (Brassicaceae),Brassica oleoracea var. italic (Brassicaceae),Brassica oleoracea var. sabellica (Brassicaceae),Apium graveolens (Api- 
aceae), Coriandrum sativum(Apiaceae), Allium cepa (Liliaceae), Lactuca sativa(Asteraceae), Capparis spinosa (Capparaceae), Asopargus officinalis (Aspargaceae), Prunus domestica (Rosaceae), Malus domestica (Rosaceae), Prunus avium (Rosaceae), Vaccinium oxycoccus (Ericaceae), Solanum lycopersicum(Solanaceae), Vitis vinifera (Vitaceae), Ginkgo biloba(Ginkgoaceae), and Sambucus canadensis (Adoxaceae), where it can also be present as glycones or conjugates of carbohydrates (Lakhanpal \& Rai, 2007; Yao Li et al., 2016).

\section{Biosynthesis of quercetin}

Quercetin biosynthesis takes place via the phenylpropanoid metabolic pathway. Initially, cinnamic acid is synthesized from phenylalanine; this reaction is catalyzed by the crucial enzyme phenylalanine ammonialyase (PAL) (Fig. 1). In particular, cinnamic acid undergoes the action of chief enzyme cinnamate 4hydroxylase $(\mathrm{C} 4 \mathrm{H})$ to produce $p$-coumaric acid. This synthesized p-coumaric acid with carboxylic group undergoes ligation with $\mathrm{CoA}$ and produces 4-coumaroyl-CoA. This particular reaction is catalyzed with the help of enzyme $p$-coumarate:CoA ligase (4-CL). The enzyme chalcone synthase (CHS) produces the naringenin chalcone from one $p$-coumaroyl-CoA and three malonyl-CoA molecules to produce essential A- and B-rings of flavonoid skeleton (i.e., C6-C3-C6). The construction of the heterocyclic C-ring occurs via chalcone isomerase $(\mathrm{CHI}$ ), which produces naringenin (a flavanone), which serves as an intermediary compound. Meanwhile, the flavanone 3 $\beta$-hydroxylase (F3H) undergoes hydroxylation of naringenin and synthesizes dihydrokaempferol. Likewise, the flavonol 3'-hydroxylase undergoes the hydroxylation reaction on dihydrokaempferol to construct dihydroquercetin. Finally, the action of the enzyme flavonol synthase on dihydroquercetin catalyzes the biosynthesis of an active and crucial flavonol : quercetin (Alrawaiq \& Abdullah, 2014; Lakhanpal \& Rai, 2007; Nabavi et al., 2020).

Differences in flavonoids arise by following the processes like methylation (more often in B-ring than Aring), hydroxylation, acylation, and glycosidation (with mono- or oligosaccharides such as glucose, galactose, xylose, rhamnose, arabinose) at different ring positions (Fig. 1). One hydroxyl group might be present in A-ring at the ortho-position to the side chain, which can be glycosylated, methylated, or carry other groups. The existence or lack of carbonyl group at the C-4 position in ring $\mathrm{C}$ is also used to categorize flavonoids. Substitution of hydroxyl groups mainly occurs at C-5 and C-7 position in A-ring, and at C-4' in B-ring, which often results in the formation of catechol function group when hydroxylation further proceeds to C-3' position in the B-ring. Flavonoid compounds with different substituents induce unique physical and chemical properties resulting in several biological activities (Brodowska, 2017; Kutchan, Gershenzon, Møller, \& Gang, 2015; W. A. Peer \& Murphy, 2006).

Regulation of the flavonoid biosynthetic pathways is carried out by interacting with various transcription factors (TFs) of different families. Gene participating in the anthocyanin pathway are differentially monitored in monocot (e.g., in maize) and dicot (e.g., inArabidopsis thaliana) plants by basic helix-loop-helix (bHLH), WD 40 proteins, and R2R3-MYB transcription factors (Petroni \& Tonelli, 2011). The combination and interaction of R2R3-MYB, bHLH, and WD 40 TFs (form MYB-bHLH-WD 40 complex) perform the activation and temporal and spatial expression of the structural genes of anthocyanin biosynthesis. In developing seeds of $A$. thaliana, TT2, TT8 and TTG1 form a ternary complex followed by activation of proanthocyanidin biosynthesis, while TTG1 (a WD40 TFs), various bHLH (GL3, EGL3, and TT8), and MYB TFs (PAP1 and PAP2) interact with each other for activating anthocyanin biosynthesis in the vegetative tissue (Baudry et al., 2004; Feller, Machemer, Braun, \& Grotewold, 2011). In Zea mays, bHLH and MYB proteins are encoded by two multi-gene families $(B / R$ and $P L / C 1$, respectively). Each member has a distinct tissue and developmental- pattern. In contrast, a WD40 protein, PAC1, is needed by both the B1 and R1 proteins for the complete activation of genes (in roots and seeds) of the anthocyanin biosynthetic pathway. Functionally active $A$. thaliana TTG1 is needed for anthocyanin pigment accumulation during the development of trichomes and roots (Galway et al., 1994), and maize PAC1 could complement ttg1 mutants of $A$. thaliana ; however, pac1 maize mutants only perform decrement in the anthocyanin pigmentation in specialized tissues (Carey, Strahle, Selinger, \& Chandler, 2004). Regulation of biosynthesis shows distinctive alteration in $A$. thaliana and maize. Three R2R3-MYB proteins (MYB11, MYB12, and MYB111) of $A$. thaliana perform spatial differential expression patterns, modulate the expression of AtFLS1 in tissue, and 
dictate specific developmental pattern (Stracke et al., 2007). ZmFLS1/2 are modulated by anthocyanin (R/B and C1/PL1) and P1 (R2R3-MYB) regulators (Falcone Ferreyra et al., 2012). Flavonols are required for the germination of pollen and conditional male-fertility in Zea mays (Mo, Nagel, \& Taylor, 1992), while maize without P1 and C1/PL1+R/B regulators are infertile (Neuffer, Coe, \& Wessler, 1997). In A. thaliana, a PFG1-3-independent flavonol accumulation starts in pollen and seeds/siliques, indicating the involvement of some unknown regulators in the flavonoid regulation and accumulation (Stracke et al., 2010).

The bHLH and MYB families have been studied to analyze their evolution from several structural and functional changes. It was found that in gymnosperm Picea mariana (black spruce), C1 like (MBF1) regulator controls the anthocyanin pathway; supporting the notion that the C1 like the class of R2 R3 MYB proteins precedes the evolutionary separation of angiosperms from the gymnosperms (Xue, Charest, Devantier, \& Rutledge, 2003). The presence of both MYB and bHLH proteins in the mosses strengthens this hypothesis, suggesting the early evolution of the bHLH-MYB complex during the development of land plants (Pires \& Dolan, 2010).

\section{Quercetin-derived compounds}

Quercetin is a bioactive natural compound, built upon the flavon structure: C6(A-ring)-C3(C-ring)-C6(Bring) (Fig. 1). The structural differences in the various flavonoid are due to the changeover of the differentially located hydrogen ion with other groups, including hydroxyl, methoxyl, and glycosyl. Additional structural variations come about due to the C-ring oxidation and its association with the B-ring. Isoquercetin is a quercetin-derived compound having attached glucose instead of the 3-OH group of quercetin. Attachment of galactose at the same portion generates another derivative, named quercetin 3-O galactoside or hyperoside. Likewise, the rhamnosyl group addition to the $3-\mathrm{OH}$ or $7-\mathrm{OH}$ group results in the development of quercetin 3 -O-rhamnoside and quercetin 7-O-rhamnoside, respectively. Disaccharides like glucose and rhamnose are also attached to quercetin and form another derivative known as rutinose or $\alpha$-L-rhamnopyranosyl-(1-6)$\beta$-D-glucopyranose. Rutin is also a vital derivative, having disaccharides at the 3 - $\mathrm{OH}$ position. Similarly, attachment of arabinofuranose to the above same position forms avicularin. Enzymatically-altered isoquercetin has ten glucose residues fixed to the $3-\mathrm{OH}$ position of quercetin, while the oligoglucosylated rutin can contain up to five more residues of glucose joined to the glucose moiety of rutin. Methylated quercetin derivatives are also found (i.e., quercetin 4'-methyl ether and tamirixetin possess an additional methyl at 4'-position). Likewise, rhamnetin 7-O-methyl quercetin also has a methyl group at the 7-OH position. Furthermore, rhamnazin is a dimethylated quercetin derivative with a methyl group at 3'- and 7-OH positions. Another methylated flavonol is isorhamnetin (3-methylquercetin), the glycosylation of which leads to narcissin (isorhamnetin 3-O-rutinoside), isorhamnetin 3-O-rutinoside-4'-O-glucoside, and isorhamnetin 3-O-rutinoside-7-O-glucoside. Quercetin derivatives having both methyl and glycosyl groups illustrate more structural distinctions (e.g., tamarixetin 3-O- $\beta$-D-glucoside has glucose at 3-position and a methyl group at 4'-position) (Magar \& Sohng, 2020).

Investigations of the biological activities of quercetin and its derivatives revealed that they possess distinct efficiencies and activities due to several modifications at significant positions of the quercetin molecule. Glycosylation usually occurs at 3- and 7-OH positions; however, methyl groups are generally associated at 3'-, 4'-, and 7-positions. Lesjak et al. (2018) studied the structural activity relation of quercetin and its derivatives on anti-inflammatory and antioxidant activities. They observed that the adjustment in quercetin structure trims down its antioxidant potential; thus the authors conclude that quercetin shows the highest potential in terms of antioxidant property, followed by tamarixetin and isorhamnetin (show equal activity) quercetin-3-O-glucuronide, isorhamnetin-3-O-glucoside, quercetin-3,5,7,3',4'-penthamethylether, and quercetin-3,4'-di-O-glucoside. Therefore, it can be concluded that the $3-\mathrm{OH}$ group plays a crucial function in antioxidant activity (Rice-Evans, Miller, \& Paganga, 1996). In terms of lipid-peroxidation inhibition, tamarixetin, and isorhamnetin (both are methylated derivatives) showed higher activities than quercetin (Lesjak et al., 2018; Santos et al., 1998).

\section{Quercetin in phytohormone signaling}


Several changes have occurred in the past, making the recent flora more adaptive than earlier. One of them is replacing of mycosporine-like amino acid (MAA) with flavonol metabolism. Marine flora started producing MAA as a UV-protectant material. Gradual evolution pushed vegetation towards nutrient-poor land, and MAA (being an N-containing compound) became costly for them; this marks the turning point where the flavonol takes over MAA's function. Flavonols proved themselves as powerful in shielding UVradiations, as the MAA (Agati et al., 2013; Cockell \& Knowland, 1999), but the C-skeletal of flavonols makes them more cost-efficient for land plants (Pollastri \& Tattini, 2011). In the meantime, flavonol, particularly quercetin derivatives, improved the water and nutrient taking ability of land plants by interacting with soil chemistry (Cesco et al., 2012) and also enabled them to build a string relationship with N-fixing bacteria and mycorrhizal fungi (Hassan \& Mathesius, 2012; Wasson, Pellerone, \& Mathesius, 2006); the mycorrhizal association with plants considered to be a peculiar event in the evolution of land flora (Field, Pressel, Duckett, Rimington, \& Bidartondo, 2015). During nodulation, flavonol acts as an auxin transport inhibitor (Ng et al., 2015), thereby enhancing the local auxin levels, further boosting nodule organogenesis (Hassan \& Mathesius, 2012). The association of land flora with bacteria and fungi using the flavonoids supports Jorgensen's hypothesis (Jorgensen, 1993).

\subsection{Quercetin-mediated auxin signaling}

Flavonols are well suited for altering auxin transport and signaling. They have the power of modifying the activities of a huge amount of proteins (Wendy Ann Peer, Blakeslee, Yang, \& Murphy, 2011; W. A. Peer \& Murphy, 2006; Santelia et al., 2008) and function as powerful reactive oxygen species (ROS) scavengers (Agati, Matteini, Goti, \& Tattini, 2007; Agati \& Tattini, 2010; Wendy Ann Peer, Cheng, \& Murphy, 2013). Quercetin disturbs the activity of serine-threonine PINOID (PID) proteins, which are responsible for the localization of PINFORMED (PIN) auxin-efflux facilitator proteins (Adamowski \& Friml, 2015; Michniewicz et al., 2007; W. A. Peer \& Murphy, 2006). Flavonoids determine the auxin gradient in the auxin level at both cellular or tissue stage by affecting auxin's catabolism (Wendy Ann Peer et al., 2011; Wendy Ann Peer et al., 2013; Zhang \& Peer, 2017), i.e., performing the function of ROS scavengers. It is still unclear whether there is an impact of flavonols-induced ROS scavenging ability on the auxin signaling (Gayomba, Watkins, \& Muday, 2017). Flavonols regulate the IAA oxidation by retarding the activity DIOXYGENASE for AUXIN OXIDATION1 (DAO1) proteins that belong to the 2-oxoglutarate and Fe(II) dependent oxygenase superfamily (Fig. 2). Besides, flavonols can reduce the level of IAA radicals generated in IAA oxidation and chelate its cofactor $\mathrm{Mn}$ (II) ion (Mathesius, 2001); hence, flavonols can be responsible for modulating auxin level, and the respective growth progresses. Previous studies also support that a hike in IAA level enhances ROS production and promotes IAA oxidation, hence repressing the auxin signaling. At the cellular level, flavonoids might perform a local buffer role for the ROS gradient and boost the plant response against the changing environment (Wendy Ann Peer et al., 2013; Zhang \& Peer, 2017). Environmental stresses induce $\mathrm{H}_{2} \mathrm{O}_{2}$ production (ROS), which triggers the specific MAP kinase such as NPK and ANP1 kinase, in tobacco and $A$. thaliana, which divert the auxin-related signaling oxidative stress signaling (Kovtun, Chiu, Tena, \& Sheen, 2000). In short, $\mathrm{H}_{2} \mathrm{O}_{2}$ activates the MAPK cascade, which represses auxin-induced activities and promotes stress protection mechanisms (Fig. 2).

Severe alterations in cellular redox-homeostasis that promote flavonol biosynthesis have been noted(Akhtar et al. 2010); this synthesized antioxidant flavonol might also regulate signaling of auxin as a large amount of flavonoids have been found near sites of high auxin concentration (Grunewald et al., 2012; Lewis et al., 2011). This is further supported by the finding that flavonoids are synthesized in the nucleus (Agati, Azzarello, Pollastri, \& Tattini, 2012; Watkins, Hechler, \& Muday, 2014), making it easy to influence MAP kinase activities. It becomes significant under stressed conditions, as re-organization of MAP kinases occurs from the cytoplasmic portion to the nuclear region for assisting the cellular re-programming (Komis, Šamajová, Ovečka, \& Šamaj, 2018).

A subclade of PIN proteins (such as PIN5, PIN6, PIN8) characterized by relatively short hydrophilic domain than the PINs of plasma membrane (PM) are found at endoplasmic reticulum (ER) (Mravec et al., 2009), and the metabolic pathways of auxin is also compartmentalizes in the same cellular structure; favored by 
the presence of different auxin metabolism related enzymes and regulatory proteins in ER (Friml \& Jones, 2010; Woodward \& Bartel, 2005). PIN proteins localized on ER are also present in earlier land plants suggesting that auxin homeostasis is the ancestral function of the PIN proteins (Viaene et al., 2014). PIN5 escorts auxin from cytoplasmic portion of ER (auxin synthesis site) to lumen of ER; hence involved in both auxin compartmentation and developing auxin gradient in the cell (Kriechbaumer, Seo, Park, \& Hawes, 2015; Mravec et al., 2009). The correlation between auxin transport and flavonoids is further supported as the cytoplasmic face of ER is the main site for flavonoid biosynthesis (Burbulis \& Winkel-Shirley, 1999). Flavonoid transportation inside the ER lumen is done by both ABC (ATP binding cassette) type and MATE (multidrug resistance and toxic ion extrusion) proteins (Fig. 2) (Kitamura, 2006).

Brunetti, Fini, Sebastiani, Gori, and Tattini (2018) hypothesized the ROS-mediated regulation of auxin transport and signaling by flavonoids. They related the quercetin concentration with auxin signaling. During the evolution of land plants, flavonoid signaling became the primary flavonoid function. In colonized land plants, signaling by flavonoid plays a significant role; it can alter organ functions and even the entire plant's entire morphology. For example, A. thalianatransparent testa (tt) mutants lacking flavonoid synthesis, have high auxin transport, and show phenotypes with heavily impaired apical dominance (Brown et al., 2001). It is also hypothesized that UVR8 is responsible for the initiation of quercetin biosynthesis for auxin signaling modulation and resulting in the busy phenotype of high UV-exposed plants (Hayes, Velanis, Jenkins, \& Franklin, 2014; Hectors, van Oevelen, Guisez, Prinsen, \& Jansen, 2012). Antioxidant flavonoids can potentially modulate the morphology (Buer, Imin, \& Djordjevic, 2010; Jansen, 2002) of the plant in both stressed (exceptionally high light exposure) and non-stresses conditions (Potters, Pasternak, Guisez, \& Jansen, 2009; Potters, Pasternak, Guisez, Palme, \& Jansen, 2007; M. Tattini, Gravano, Pinelli, Mulinacci, \& Romani, 2000; Massimiliano Tattini et al., 2017). Plants exposed to UV-radiation induced several modifications in individual organs and even in the whole plant, together with a high level of quercetin derivatives (Agati et al., 2012). Both moss (Physcomitrella patens ) and angiosperm (A. thaliana) respond similarly against UV exposure, particularly increasing the production of quercetin-derivatives (Wolf, Rizzini, Stracke, Ulm, \& Rensing, 2010). Recent evidence suggested that in P. patens and Marchantia polymorpha (liverwort), UVR8 mediates HY5 (ELONGATED HYPOCOTYL 5) transcription expression and accumulation of CHS (CHALCONE SYNTHASE) protein under UV-B exposure. Notably, this HY5 regulates the expression of genes MYB12 and MYB111, called PFG (PRODUCTION OF FLAVONOL GLYCOSIDES) (Stracke et al., 2010) in both UV-B and high white light exposure. PIN-flavonoid was found to alter the plant's architecture (particularly bryophytes). However, some researchers reported that 'ancestral' PIN6 protein in A. thaliana and the PINA present inP. patens could be localized in ER and PM (Friml \& Jones, 2010; Simon et al., 2016). Bennett et al. (2014) reported that PINs protein in the $P$. patens gave a very high response to flavonol naringenin and regulated the shoot growth; thus, it opened the door towards the PIN/flavonoid-mediated plant shape regulation in bryophytes and angiosperms. Quercetin-derivatives are also reported to strongly influence the signaling pathways of ABA; as it antagonizes ABA-regulated stomatal closure in both tomato and A. thaliana. Guard cells of $A$. thaliana with high quercetin concentration show greater aperture of stomata compared to quercetin-deficient cells (Watkins et al., 2014). Likewise, tomato mutants with low flavonol show high ROS content and a small aperture of stomata compared to another tomato mutant having high quercetin content (Watkins, Chapman, \& Muday, 2017). $\mathrm{H}_{2} \mathrm{O}_{2}$ is an important secondary messenger in the ABA-signaling network and is considered essential for closing stomata (P. Wang \& Song, 2008). Watkins et al. (2014) observed the cytoplasmic and, more specifically, the nuclear position of flavonol distribution in A. thaliana guard cells; both quenching of $\mathrm{H}_{2} \mathrm{O}_{2}$ and inhibition of MAP kinase activities by quercetin act against the ABA-induced guard cell regulation (Fig. 3) (Danquah, de Zelicourt, Colcombet, \& Hirt, 2014; Jammes et al., 2009).

ABA is also involved in flavonol biosynthesis (Berli, Fanzone, Piccoli, \& Bottini, 2011; Berli et al., 2010), and ABA-induced signaling is correlated with light signaling (Bechtold et al., 2008; F. Wang et al., 2018). This correlation supports the increased flavonol synthesis under high light conditions (with or without UVradiation). Enhanced foliar ABA level under high luminance is due to increases in the de-glucosylation process of inactive ABA-glucoside (ABA-GE), rather than from newly synthesized ABA molecules (Lee et 
al., 2006; Massimiliano Tattini et al., 2017). The main concept is that $\beta$-glucosidase (BG1), responsible for the removal of free ABA molecule from its glucoside bounded (ABA-GE) form, is ER-localized (Lee et al., 2006); viz. the flavonoid synthesizing site. It is proposed that excessive light initiates ABA's from ABA-GE and enhances the level of local ABA, including flavonol biosynthesis (Fig. 3). Flavonol-mediated ABA-signaling regulation provides an extra modulator for stomatal movement. Availability of auxin, ABA, and quercetin at the vicinity of ER connects themselves for flavonol mediated signaling regulating both Auxin and ABA. However, the actual mechanism of ABA-flavonol-mediated acclimation of plants against a drastically changing environment is further under investigation (Leng, Yuan, \& Guo, 2013).

\subsection{Quercetin-mediated ABA signaling}

Flavonols-mediated regulation of ABA signaling pathway is considered to be executed by countering oxidative burst, and substantial $\mathrm{H}_{2} \mathrm{O}_{2}$ production, leading to more ABA synthesis (Choudhury, Rivero, Blumwald, \& Mittler, 2016; Tossi, Lamattina, \& Cassia, 2009; Watkins et al., 2017; Watkins et al., 2014). In A. thaliana , ethylene-stimulated flavonol accumulation was found to act against ABA-encouraged stomatal shutting (Watkins et al., 2014). Watkins et al. (2017) observed that the tomato anthocyanin without (aw) mutant supports flavonols at the cost of anthocyanin synthesis, and showed a high amount of open stomata than wildtype tomato. Moreover, protein UVR8 was observed to control stomatal movements via regulating important components of flavonol-synthetic machinery (such as HY5) and ABA-signaling pathways, for example, NO and $\mathrm{H}_{2} \mathrm{O}_{2}$ (Tossi, Lamattina, Jenkins, \& Cassia, 2014). This encourages the concept of participation of ABAsignaling in UV-B irradiated metabolic re-programming, and this might involve NO-motivated upregulation of early flavonoid genes that results in flavonoid biosynthesis (Fig. 3) (A.-H.-Mackerness, John, Jordan, \& Thomas, 2001; Tossi, Cassia, Bruzzone, Zocchi, \& Lamattina, 2012).

Guard cells have a high quercetin content low $\mathrm{H}_{2} \mathrm{O}_{2}$, which is needed for ABA-induced stomatal closure (P. Wang \& Song, 2008). Generally, quercetin remains distributed in the nucleus and slightly lower in subcellular organelles, except for guard cell vacuoles (Watkins et al., 2017). It can be hypothesized that the antagonistic effect of quercetin on ABA-mediated stomatal shutting might not only be due to its potential of edging $\mathrm{H}_{2} \mathrm{O}_{2}$ accumulation but also via suppressing MAPKs activities that work downstream of $\mathrm{H}_{2} \mathrm{O}_{2}$ to confer stomatal movements (Fig. 3) (Danquah et al., 2014; Jammes et al., 2009).

Flavonols remain located in the nucleus (Agati et al., 2012; Feucht, Schmid, \& Treutter, 2014). Their participation in the re-orientation of cellular metabolism in response to the high light irradiance is well-described, including cytoplasm to nucleus re-allocation of MAPKs (Komis et al., 2018). Additionally, flavonols can manipulate the ABA signaling pathway by interfering with members of the SnRK2 family (primary signaling components). Flavonols are strongly opposed to the activity of serine/threonine protein kinases (e.g., PID (PINOID) proteins that participate in the differential circulation of PIN-formed proteins) (Kuhn et al., 2017). It is evident that the PP2A (protein phosphatases type 2C) and PID proteins function antagonistically on phosphorylation of PIN proteins (Michniewicz et al., 2007) and, it was hypothesized that quercetin might place a similar kind of control on the ABA-SnRK2-PP2C signaling network (Fig. 3) (Brunetti et al., 2018). Although modulation of protein kinase activities by the action of quercetin has been observed in animals, this modulating activity in plant cell metabolism remains un-elucidated and faces major methodological problems, particularly in the case of guard cell metabolism.

Quercetin can alter the content of both primary and secondary components, and might act as a key compound of the regulatory route of the ABA-signaling pathway (Hirayama \& Shinozaki, 2007; Wagner, 2011). The ABA-flavonol relationship shows some similarity with the auxin-flavonol relationship. Auxins promote quercetin synthesis (over kaempferol synthesis) and, in-turn, quercetin efficiently alters the transportation of auxin (Hayes et al., 2014). The UV-B radiated A. thaliana showed high HY5 levels and reduced auxin signaling (Hayes et al., 2014), leading to more quercetin synthesis (Brunetti et al., 2018).

\section{Role of quercetin in plants}

Flavonoids are essential secondary metabolites synthesized in almost all plant parts under different plantenvironment communication. They are associated with numerous physiological activities, including the taste 
and smell of fruits, flowers, and vegetables, and color development, making them that compose them essential compounds in the context of insects, birds, and animal attraction, facilitating seed dispersal. Likewise, flavonoids are important for plants in defending against noxious herbivores and insects (Alseekh et al., 2020). In a few cases, they can behave as highly toxic substances (Mierziak, Kostyn, \& Kulma, 2014), and in some, they can retard the development of pathogens (Alseekh et al., 2020). Flavonoids impart an important function in micro-organisms' symbiotic interactions (Abdel-Lateif, Bogusz, \& Hocher, 2012). For instance, chrysin and luteolin are biosynthesized in legumes for eliciting the signaling pathway for Rhizobacteriuminduced symbiosis or developing root nodule in nitrogen-fixing bacteria. Flavonoids also help the plants to overcome their the competition by inhibiting the germination and growth of challenging plants (Hartwig, Joseph, \& Phillips, 1991; Reddy, Reddy, Scheffler, Wienand, \& Reddy, 2007).

Hydroxylation of flavonoids has been found to slow the anti-fungal and anti-pathogenic activities. Plants are often sessile and cannot move, so they have evolved various innovative techniques to exclude deleterious effects developed due to environmental pressure, including thermal changes, heavy metals, drought, and UV-irradiations. All of them forced the plants to produce many free radicals, and the flavonoids are engaged with scavenging the stress-induced ROS production (Ryan, Swinny, Markham, \& Winefield, 2002).

Flavonoids are secondary metabolites responsible for distinct red, purple, and blue (anthocyanin) pigments of various plant tissues (Winkel-Shirley, 2001). These compounds attract and recruit the pollinators/insects for pollination and seed dispersal. Secondary metabolites give a display to the flower, which guards leaf cells against the photo-oxidative damage, and improves nutrient retrieval capability during senescence (Feild, Lee, \& Holbrook, 2001). Among the flavonoids, flavonols may be the most ancient metabolites, as synthesized in ferns and even in mosses, performing a wide variety of physiological functions (Stafford, 1991).

One crucial role of quercetin is to adjust polar auxin transports, even in small quantities (Wendy Ann Peer \& Murphy, 2007). The flavonols were also reported to support the plant arbuscular mycorrhizal association (Abdel-Lateif et al., 2012), as they act as auxin transport regulators during nodule formation (Ng et al., 2015). It is now very evident that during shade to sun transitions, quercetin derivatives replace the hydroxycinnamic acid derivatives in both epidermal cells and secretory trichomes (Agati, Galardi, Gravano, Romani, \& Tattini, 2002; M. Tattini et al., 2000), even though hydroxycinnamates have a higher molar extinction coefficient than the flavonols over the UV-B range of the solar spectrum (Agati et al., 2013). From this, it can be hypothesized that supplying leaves with flexible metabolites competent of providing numerous occupations, at the charge of highest potential to soak up the shortest solar wavelengths (Pollastri \& Tattini, 2011).

Quercetin and related flavonols are always present in plants, but in differing amounts. There is a lot of information about the effect of in-built quercetin on plant physiology. But the sitability of making concludes based on the consequence of exogenously applied quercetin on the plants is debatable. Recent researche has revealed more beneficial roles of quercetin on plants.

Suppression of carotenoid photobleaching by quercetin suggested quercetin-mediated improvements in carbon assimilation (Takahama, 1984). Earlier in vitro research of Ylstra et al. (1992) using quercetin depicted its promotive role in the development, germination, and growth of pollen tubes. In $M$. hupehensis, quercetin application was observed to retard the indole 3-butyric acid-induced NO production (Gao \& Yang, 2011). Quercetin is a well-known auxin inhibitor, so their exogenous treatment was restricted to auxin transportation (Imin, Nizamidin, Wu, \& Rolfe, 2007). The researchers argued that the transport inhibition could be helpful for the plant, as high localized auxin content might be necessary to establish root primordial (Gao \& Yang, 2011). Quercetin may work as a protein kinase inhibitor (Pan et al., 2005), ATPase inhibitor (Takahashi, Sert, Kelmer-Bracht, Bracht, \& Ishii-Iwamoto, 1998), and electron transport inhibitor (Moreland \& Novitzky, 1987). Transcriptional analysis was performed using quercetin treated tobacco seedlings by Mahajan and Yadav (2013). It was reported that quercetin regulates the activity of antioxidant enzymes viz., glutathione reductase (GR), glutathione peroxidase (GP), glutathione-S-transferase (GST), ascorbate peroxidase (APX), superoxide dismutase (SOD) and peroxidase (POX) enzymes. The quercetin works in a dose-dependent manner, and the optimum dose proves beneficial for the particular plant. This research further promotes the antioxidative property of quercetin. 
The application of quercetin was reported to promote polyamines (especially spermidine) in Eucalyptus (Prado et al., 2015). The same experiment also revealed that the quercetin-mediated enhanced ascorbic acid content and its antioxidant nature. Quercetin could promote the fruit loosening in oranges (Yuan, Kender, $\&$ Burns, 2003). Experimental studies clarify that supplementation of quercetin inhibits root growth while it enhanced lateral root formation. Quercetin application also improved the cell wall thickening of parenchyma and cortical cell layer by increasing the lignification (Franco et al., 2015).

Quercetin modulates root growth by limiting cell proliferation and enhancing the cell elongation phase. It is assumed that the meristematic region of root faces high limitations of cell proliferation under quercetin treatment (Tohge \& Fernie, 2016); it might depend on cytokinin perception. In an experiment conducted by Kurepa, Shull, and Smalle (2016), they observed that paraquat, a ROS-producing compound, generates a lesser amount of ROS under quercetin treatment. These authors also analyzed protein oxidation in $A$. thaliana and observed the protective role, which is evident from a low accumulation of the derivatized proteins. Even in Nicotiana tabacum andLemna gibba, they observed the counteraction of quercetin over paraquat's toxic effects.

\section{Quercetin in stress mitigation}

Flavonoids are a diverse group of secondary metabolites, performing a vast range of biological functions, including stress protection. The fluctuating environment alters the flavonoid synthesizing pathway, indicating flavonoid's stress protective mechanisms in plants (Chalker-Scott, 1999). Increased flavonols under biotic and abiotic stress indicate their stress-filter function in plants. Having OH-group at the 3-position of flavonoid skeleton makes flavonols more efficient ROS scavengers, inhibits ROS aggregation, and allows metal chelation. The antioxidant property of quercetin makes it a more reliable source of eradicating stress as most of the stress harm the plant by generating oxidative stress (via ROS production). Unfortunately, only a few experiments were performed to put forward its tremendous stress mitigation power. The cross-talk of quercetin with ABA further confers its stress halting capabilities. The quercetin reduces the level of $\mathrm{H}_{2} \mathrm{O}_{2}$ (requires for ABA-induced stomatal closure) that reduces the stomatal closure, which helps the plants to face stress in a less savior manner (Agati et al., 2011; Agati, Stefano, Biricolti, \& Tattini, 2009).

Flavonoids can resist the toxin effects generated by heavy metals. Root exudates of Zea mays exposed to aluminum toxicity were rich in flavonoids (Kidd, Llugany, Poschenrieder, Gunsé, \& Barceló, 2001), thereby confirming flavonoid-mediated heavy metal amelioration in plants. Keilig and Ludwig-Müller (2009) noted that both quercetin and naringenin reversed the harmful consequences caused by cadmium and zinc ions in A. thaliana . Likewise, Parvin et al. (2019) explored the morpho-physiological traits of salt-treated tomato and observed the encouraging role of quercetin. They indicated the enhanced production of chlorophylls and carotenoids by quercetin, and suggest suggested that this might be due to quercetin induced lower ratio of $\mathrm{Na}^{+} / \mathrm{K}^{+}$, lashed out osmotic stress, and ROS production. These authors studied several enzymatic and non-enzymatic antioxidants and concluded the positive role of quercetin for plant health. Quercetin was reported to reduce the activity of lipoxygenase, SOD, catalase, and it also reduced the malonyldialdehyde content. Meanwhile, quercetin treatment of tomato enhanced ascorbate and glutathione (GSH) content and, in contrast, led to reduced activities of glutathione peroxidase, APX, GST, and monodehydroascorbate reductase. Furthermore, these authors also highlighted that the quercetin improved the ratio of ascorbate/dehydroascorbate and glutathione/glutathione disulfide. This finding suggests that the gene GmGSTL1 (fromGlycine max ) that encodes GST plays a prominent role in stress tolerance. Stress conditions result in up-regulation of GmGSTL1 gene responsible protection and increased survival, and the functional role of this was also confirmed in A. thaliana and tobacco cell line model (Chan \& Lam, 2014).

Phenolic compounds act as an excellent antioxidant, although phenoxyl radicals generated by antioxidative reactions are pro-oxidative (Bartwal, Mall, Lohani, Guru, \& Arora, 2012). Thus, enzymatic scavenging of these phenoxyl radicals to rejuvenate and sustain the pool of active phenolic antioxidants is necessary for managing homeostasis. Chan and Lam (2014) indicated that TaGSTL1 could arbitrate GSH-dependent reduction of the derivatives for regenerating active quercetin, which works like a proton donor to the oxidative species. Oxidized quercetin derivatives further react with GSH and water molecules to develop an adduct, 
which is recycled as a substrate for enzyme GSTL (Dixon \& Edwards, 2010). Hence, GSTL1 is considered a possible missing bond between recycling and maintaining the antioxidative power-driven from phenolic compounds. Experimental data supports the notion that GmGSTL1 gene codes for a serviceable protein that hunts the ROS generated by abiotic stress. The quercetin mediated stress alleviation suggests that both quercetin and GSTL perform a similar protective function (Chan \& Lam, 2014).

Dihydroxy B ring flavonoids, like luteolin 7-O and quercetin 3-O-glycosides, participate in UV-radiation stimulated ROS (Agati et al., 2012; Fini, Brunetti, Di Ferdinando, Ferrini, \& Tattini, 2011). The capacity of flavonoids in scavenging free radicals was directly coupled with the presence and location of - $\mathrm{OH}$ groups in A- and B- rings (Mierziak et al., 2014). This effect is enhanced by the attached catechol moiety to ring $\mathrm{B}$ at the double $\mathrm{C} 2=\mathrm{C} 3$ bond, and more still with the additional $\mathrm{C} 3-\mathrm{OH}$. Moreover, flavonoid structure with chelated metal cations (such as $\mathrm{Cu}^{2+}, \mathrm{Fe}^{2+}, \mathrm{Al}^{3+}$, and $\mathrm{Zn}^{2+}$ ) could resist the peroxidation of lipids that rely on $\mathrm{Fe}^{2+}$ and $\mathrm{Fe}^{3+}$ (Arora, Nair, \& Strasburg, 1998). Flavonoids further impart an important role of modulating the transport system of auxin (Wendy Ann Peer \& Murphy, 2007) that is frequently taking place by reverse phosphorylation imparting a particular protein kinase (DeLong, Mockaitis, \& Christensen, 2002). Furthermore, flavonoids are known for enriching soil present nutritional compounds when they are inadequately accessible using ATP-binding cassette-type transporter. They also ensure the liberation of metal cations needed for the optimum growth and development of plants (Badri et al., 2008; Sugiyama, Shitan, \& Yazaki, 2007).

The role of quercetin as an antioxidant compound of the cell has been analyzed from ancient times. The specialized structure of quercetin develop impairs an antioxidant property and helps in quenching off the ROS species generated by the cells. Flavonoids with 3-OH and 3',4'-catechol are ten times more potent towards the peroxynitrite, a well-known RNS scavenger (Haenen, Paquay, Korthouwer, \& Bast, 1997). Enhanced quercetin levels avoid the metal/non-metal-induced oxidative damage due to its free 3-OH group (Arora et al., 1998; Ratty \& Das, 1988) that does believe in upgrading the flavonoid-radical stability. For quercetin's chelating action, the catechol-group is its best partner and has been approved by different studies. This compound slows lipid peroxidation by scavenging its free radicals (Alrawaiq \& Abdullah, 2014). While quenching the free radicals and transition metal binding, quercetin undergoes an oxidation process and produces the semiquinone radical. These semiquinone radicals further face another oxidation and generate the quercetin quinone. Quinone interacts with protein thiols, which is eradicated by glutathione and reduces its level (Metodiewa, Jaiswal, Cenas, Dickancaité, \& Segura-Aguilar, 1999). Compared to aglycons, glycosylated flavonoids have reduced in vitro antioxidant property (Cavia-Saiz et al., 2010; Mishra, Priyadarsini, Kumar, Unnikrishnan, \& Mohan, 2003). Glycosylation of quercetin also slows its hypochlorite scavenging ability (Firuzi, Mladênka, Petrucci, Marrosu, \& Saso, 2004), superoxide quenching property (Sun, Fu, Chen, Jiang, \& Pan, 2010), and its potential to reduce Fe(III) to Fe (Tanigawa, Fujii, \& Hou, 2007).

Being a secondary product, quercetin's antimicrobial activities are well elucidated in plants. Quercetin inhibits the synthesis of nucleic acids by repressing enzymes, e.g., DNA gyrase. Enzyme DNA gyrase is essential for DNA replication, and this is limited to prokaryotes; making it a smart target for developing antibacterial drugs (Plaper et al., 2003). Initially, (Ohemeng, Schwender, Fu, \& Barrett, 1993) investigated the DNA gyrase inhibiting quercetin's activity in Escherichia coli. Further research based on in-silico analysis revealed that the B subunit of DNA gyrase of bacteria Mycobacterium tuberculosis and Mycobacterium smegmatis might be the quercetin target (Suriyanarayanan, Shanmugam, \& Santhosh, 2013). This study was further supported when it became clear that quercetin binds to subunit B of gyrase and subsequently blocked the ATP-binding pocket by developing a hydrogen bond through 3, 5, and 7-OH groups to amino acids residues of gyrase (Górniak, Bartoszewski, \& Króliczewski, 2018).

Moreover, Wu, Zang, He, Pan, and Xu (2013) reported quercetin-based blockage of the ATP-binding pocket of D-alanine-D-alanine. Similarly, the other related flavonoids, like kaempferol and chrysin much-repressed gyrase activity in E. coli . It is concluded that the hydroxyl group of flavonoids permit a better connection with gyrase than the methoxy groups. Molecular docking studies suggest another way of flavonoid-mediated DNA gyrase inhibition, indicating that flavonoids suppress the supercoiling of DNA by competing with 
the ATP binding site of the B subunit of gyrase (GyrB) (Fang et al., 2016). This might be due to the flavonoid binding with DNA, which forms the DNA-gyrase complex and induces DNA cleavage (Plaper et al., 2003). 3-OH, 5-OH, 7-OH, and 4-carbonyl groups of flavonoids are highly dynamic for interacting with GyrB residues (Fang et al., 2016). Not only gyrases but also topoisomerases are necessary for DNA replication. Recent studies have noted that these enzymes are molecular targets for flavonoids. Both flavonols and flavones have a nucleic acid binding capacity have been propsed to block the helicase activity. Xu and Lee (2001) found that myricetin - a quercetin-related compound - inhibits the helicases, such as DnaB and RecBCD helicase/nuclease, in E. coli. The same flavonol has been proposed to suppress RNA and DNA polymerases, as well as the transcriptases (Ono, Nakane, Fukushima, Chermann, \& Barre-Sinoussi, 1990) and the telomerase (Griep, Blood, Larson, Koepsell, \& Hinrichs, 2007). The impact of quercetin and its related compounds on DNA and RNA synthesis related enzymes has enhanced quercetin's reputation flavonoids.

\section{Conclusions and future prospective}

Quercetin is the particular class of bioactive flavonoid built upon the flavon structure that plays a remarkable role in facilitating numerous plant functions. However, it is still regarded as an enigmatic compound. It is becoming highly apparent that quercetin is a multifaceted compound in plants. This review gives a better understanding of several key characteristic features related to flavonoids, especially quercetin, including their potential sources in plants. Interestingly, recent reports on flavonoid biosynthesis show their regulation at the molecular level. Thus, signal transduction pathways in plants cover a significant part of this review. Furthermore, recent detailed IAA and ABA-mediated signaling is also reviewed, providing a better understanding of how flavonoids, especially quercetin, play several major functions in plants (i.e., antioxidant and antimicrobial compounds). Apart from this, quercetin also plays a critical role in triggering several plant physiological attributes such as seed germination, growth, photosynthesis, and yield traits under healthy and stressful environment. Quercetin plays a significant role in maintaining the balanced concentration of ROS and lipid peroxidation and augmenting several physiological functions to confer environmental stress tolerance. The most remarkable role of flavonoids is providing a shield against harmful UV rays. Nevertheless, quercetin is a potent flavonoid with a diverse function in plants.

Due to the remarkable role of quercetin in plant physio-biochemical responses under a healthy and stressful environment, further research should be directed to more accurately identify metabolic, molecular, and signaling regulators involved in environmental stress tolerance, as well as the cross-talk between quercetin and plant hormones. Such work would contribute to a better understanding of the mechanisms involved in crop improvement and sustainable agricultural practices.

\section{Authors' contributions}

SH: an idea of the article; PS, YA: drafting of the article; SH, AB: significant revision and precious intellectual input; all authors: final acceptation. We apologize to the authors whose previous works have not been cited due to space limitations.

\section{Declaration of competing interest}

The authors announce that they have no known contending financial interests or personal interaction that might have appeared to manipulate the work reported in this paper.

\section{References}

A.-H.-Mackerness, S., John, C. F., Jordan, B., \& Thomas, B. (2001). Early signaling components in ultraviolet-B responses: Distinct roles for different reactive oxygen species and nitric oxide. FEBS Letters, 489 (2-3), 237-242. https://doi.org/10.1016/s0014-5793(01)02103-2

Abdel-Lateif, K., Bogusz, D., \& Hocher, V. (2012). The role of flavonoids in the establishment of plant roots endosymbioses with arbuscular mycorrhiza fungi, rhizobia and Frankia bacteria. Plant Signaling 83 Behavior, 7 (6), 636-641. https://doi.org/10.4161/psb.20039 
Adamowski, M., \& Friml, J. (2015). PIN-dependent auxin transport: action, regulation, and evolution. Plant Cell, 27 (1), 20-32. https://doi.org/10.1105/tpc.114.134874

Agati, G., Azzarello, E., Pollastri, S., \& Tattini, M. (2012). Flavonoids as antioxidants in plants: Location and functional significance. Plant Science, $196,67-76$. https://doi.org/10.1016/j.plantsci.2012.07.014

Agati, G., Biricolti, S., Guidi, L., Ferrini, F., Fini, A., \& Tattini, M. (2011). The biosynthesis of flavonoids is enhanced similarly by UV radiation and root zone salinity in L. vulgare leaves. Journal of Plant Physiology, 168 (3), 204-212. https://doi.org/10.1016/j.jplph.2010.07.016

Agati, G., Brunetti, C., Di Ferdinando, M., Ferrini, F., Pollastri, S., \& Tattini, M. (2013). Functional roles of flavonoids in photoprotection: New evidence, lessons from the past. Plant Physiology and Biochemistry, 72 , 35-45. https://doi.org/10.1016/j.plaphy.2013.03.014

Agati, G., Galardi, C., Gravano, E., Romani, A., \& Tattini, M. (2002). Flavonoid distribution in tissues of Phillyrea latifolia L. leaves as estimated by microspectrofluorometry and multispectral fluorescence microimaging. Photochemistry and Photobiology, 76 (3), 350. https://doi.org/10.1562/00318655(2002)0760350FDITOP2.0.CO2

Agati, G., Matteini, P., Goti, A., \& Tattini, M. (2007). Chloroplast-located flavonoids can scavenge singlet oxygen. New Phytologist, 174 (1), 77-89. https://doi.org/10.1111/j.1469-8137.2007.01986.x

Agati, G., Stefano, G., Biricolti, S., \& Tattini, M. (2009). Mesophyll distribution of 'antioxidant' flavonoid glycosides in Ligustrum vulgare leaves under contrasting sunlight irradiance. Annals of Botany, 104 (5), 853-861. https://doi.org/10.1093/aob/mcp177

Agati, G., \& Tattini, M. (2010). Multiple functional roles of flavonoids in photoprotection. New Phytologist, 186 (4), 786-793. https://doi.org/10.1111/j.1469-8137.2010.03269.x

Ahmed, S. I., Hayat, M. Q., Tahir, M., Mansoor, Q., Ismail, M., Keck, K., \& Bates, R. B. (2016). Pharmacologically active flavonoids from the anticancer, antioxidant and antimicrobial extracts of Cassia angustifolia Vahl. BMC Complementary and Alternative Medicine, 16 (1), 460-460. https://doi.org/10.1186/s12906-016$1443-\mathrm{z}$

Alrawaiq, N. S., \& Abdullah, A. (2014). A review of flavonoid quercetin: Metabolism, bioactivity and antioxidant properties.International Journal of PharmTech Research, 6 , 933-941.

Alseekh, S., Ofner, I., Liu, Z., Osorio, S., Vallarino, J., Last, R. L., .. Fernie, A. R. (2020). Quantitative trait loci analysis of seed-specialized metabolites reveals seed-specific flavonols and differential regulation of glycoalkaloid content in tomato. Plant Journal, 103 (6), 2007-2024. https://doi.org/10.1111/tpj.14879

Arora, A., Nair, M. G., \& Strasburg, G. M. (1998). Structure-activity relationships for antioxidant activities of a series of flavonoids in a liposomal system. Free Radical Biology and Medicine, 24 (9), 1355-1363. https://doi.org/10.1016/s0891-5849(97)00458-9

Badri, D. V., Loyola-Vargas, V. M., Broeckling, C. D., De-la-Pena, C., Jasinski, M., Santelia, D., .. . Vivanco, J. M. (2008). Altered profile of secondary metabolites in the root exudates of ArabidopsisATP-binding cassette transporter mutants. Plant Physiology, 146 (2), 762-771. https://doi.org/10.1104/pp.107.109587

Bartwal, A., Mall, R., Lohani, P., Guru, S. K., \& Arora, S. (2012). Role of secondary metabolites and brassinosteroids in plant defense against environmental stresses. Journal of Plant Growth Regulation, 32 (1), 216-232. https://doi.org/10.1007/s00344-012-9272-x

Baudry, A., Heim, M. A., Dubreucq, B., Caboche, M., Weisshaar, B., \& Lepiniec, L. (2004). TT2, TT8, and TTG1 synergistically specify the expression of BANYULS and proanthocyanidin biosynthesis inArabidopsis thaliana . Plant Journal, 39 (3), 366-380. https://doi.org/10.1111/j.1365-313X.2004.02138.x

Bechtold, U., Richard, O., Zamboni, A., Gapper, C., Geisler, M., Pogson, B., ... Mullineaux, P. M. (2008). Impact of chloroplastic- and extracellular-sourced ROS on high light-responsive gene expression in Arabidopsis 
. Journal of Experimental Botany, 59 (2), 121-133. https://doi.org/10.1093/jxb/erm289

Becker, C., Klaering, H.-P., Schreiner, M., Kroh, L. W., \& Krumbein, A. (2014). Unlike quercetin glycosides, cyanidin glycoside in red leaf lettuce responds more sensitively to increasing low radiation intensity before than after head formation has started. Journal of Agricultural and Food Chemistry, 62 (29), 6911-6917. https://doi.org/10.1021/jf404782n

Bennett, T. A., Liu, M. M., Aoyama, T., Bierfreund, N. M., Braun, M., Coudert, Y., ... Harrison, C. J. (2014). Plasma membrane-targeted PIN proteins drive shoot development in a moss. Current Biology, 24 (23), 2776-2785. https://doi.org/10.1016/j.cub.2014.09.054

Berli, F. J., Fanzone, M. n., Piccoli, P., \& Bottini, R. n. (2011). Solar UV-B and ABA are involved in phenol metabolism of Vitis vinifera L. increasing biosynthesis of berry skin polyphenols. Journal of Agricultural and Food Chemistry, 59 (9), 4874-4884. https://doi.org/10.1021/jf200040z

Berli, F. J., Moreno, D., Piccoli, P., Hespanhol-Viana, L., Silva, M. F., Bressan-Smith, R., ... Bottini, R. (2010). Abscisic acid is involved in the response of grape (Vitis vinifera L.) cv. Malbec leaf tissues to ultraviolet-B radiation by enhancing ultraviolet-absorbing compounds, antioxidant enzymes and membrane sterols. Plant, Cell $\mathscr{E}$ Environment, 33 (1), 1-10. https://doi.org/10.1111/j.1365-3040.2009.02044.x

Brodowska, K. M. (2017). Natural flavonoids: classification, potential role, and application of flavonoid analogues. European Journal of Biological Research, 7 (2), 108-123. https://doi.org/10.5281/zenodo.545778

Brown, D. E., Rashotte, A. M., Murphy, A. S., Normanly, J., Tague, B. W., Peer, W. A., .. Muday, G. K. (2001). Flavonoids act as negative regulators of auxin transport in vivo in Arabidopsis . Plant Physiology, 126 (2), 524-535. https://doi.org/10.1104/pp.126.2.524

Brunetti, C., Fini, A., Sebastiani, F., Gori, A., \& Tattini, M. (2018). Modulation of phytohormone signaling: A Primary function of flavonoids in plant-environment interactions. Frontiers in Plant Science, 9 , 10421042. https://doi.org/10.3389/fpls.2018.01042

Buer, C. S., Imin, N., \& Djordjevic, M. A. (2010). Flavonoids: New roles for old molecules. Journal of Integrative Plant Biology, 52 (1), 98-111. https://doi.org/10.1111/j.1744-7909.2010.00905.x

Burbulis, I. E., \& Winkel-Shirley, B. (1999). Interactions among enzymes of the Arabidopsis flavonoid biosynthetic pathway.Proceedings of the National Academy of Sciences of the United States of America, 96 (22), 12929-12934. https://doi.org/10.1073/pnas.96.22.12929

Carey, C. C., Strahle, J. T., Selinger, D. A., \& Chandler, V. L. (2004). Mutations in the pale aleurone color1 regulatory gene of theZea mays anthocyanin pathway have distinct phenotypes relative to the functionally similar TRANSPARENT TESTA GLABRA1 gene inArabidopsis thaliana . Plant Cell, 16 (2), 450-464. https://doi.org/10.1105/tpc.018796

Cavia-Saiz, M., Busto, M. D., Pilar-Izquierdo, M. C., Ortega, N., Perez-Mateos, M., \& Muniz, P. (2010). Antioxidant properties, radical scavenging activity and biomolecule protection capacity of flavonoid naringenin and its glycoside naringin: A comparative study. Journal of the Science of Food and Agriculture, 90 (7), 1238-1244. https://doi.org/10.1002/jsfa.3959

Cesco, S., Mimmo, T., Tonon, G., Tomasi, N., Pinton, R., Terzano, R., ... Nannipieri, P. (2012). Plantborne flavonoids released into the rhizosphere: impact on soil bio-activities related to plant nutrition. A review. Biology and Fertility of Soils, 48 (2), 123-149. https://doi.org/10.1007/s00374-011-0653-2

Chalker-Scott, L. (1999). Environmental significance of anthocyanins in plant stress responses. Photochemistry and Photobiology, 70 (1), 1-9. https://doi.org/10.1111/j.1751-1097.1999.tb01944.x

Chan, C., \& Lam, H.-M. (2014). A putative lambda class glutathione S-transferase enhances plant survival under salinity stress. Plant and Cell Physiology, 55 (3), 570-579. https://doi.org/10.1093/pcp/pct201 
Choudhury, F. K., Rivero, R. M., Blumwald, E., \& Mittler, R. (2016). Reactive oxygen species, abiotic stress and stress combination.Plant Journal, 90 (5), 856-867. https://doi.org/10.1111/tpj.13299

Cockell, C. S., \& Knowland, J. (1999). Ultraviolet radiation screening compounds. Biological Reviews of the Cambridge Philosophical Society, 74 (3), 311-345. https://doi.org/10.1017/s0006323199005356

Cook, N. C., \& Samman, S. (1996). Flavonoids - Chemistry, metabolism, cardioprotective effects, and dietary sources. Journal of Nutritional Biochemistry, 7 (2), 66-76. https://doi.org/10.1016/S0955-2863(95)00168-9

Danquah, A., de Zelicourt, A., Colcombet, J., \& Hirt, H. (2014). The role of ABA and MAPK signaling pathways in plant abiotic stress responses. Biotechnology Advances, 32 (1), 40-52. https://doi.org/10.1016/j.biotechadv.2013.09.006

DeLong, A., Mockaitis, K., \& Christensen, S. (2002). Protein phosphorylation in the delivery of and response to auxin signals. InAuxin Molecular Biology (eds C. Perrot-Rechenmann \& G. Hagen), pp. 285-303. Springer Netherlands, Dordrecht.

Dixon, D. P., \& Edwards, R. (2010). Roles for stress-inducible lambda glutathione transferases in flavonoid metabolism in plants as identified by ligand fishing. Journal of Biological Chemistry, 285 (47), 36322-36329. https://doi.org/10.1074/jbc.M110.164806

Falcone Ferreyra, M. L., Casas, M. I., Questa, J. I., Herrera, A. L., Deblasio, S., Wang, J., .. Casati, P. (2012). Evolution and expression of tandem duplicated maize flavonol synthase genes. Frontiers in Plant Science, 3 , 101-101. https://doi.org/10.3389/fpls.2012.00101

Fang, Y., Lu, Y., Zang, X., Wu, T., Qi, X., Pan, S., \& Xu, X. (2016). 3D-QSAR and docking studies of flavonoids as potent Escherichia coli inhibitors. Scientific Reports, 6 , 23634-23634. https://doi.org/10.1038/srep23634

Feild, T. S., Lee, D. W., \& Holbrook, N. M. (2001). Why leaves turn red in autumn. the role of anthocyanins in senescing leaves of red-osier dogwood? Plant Physiology, 127 (2), 566-574. https://doi.org/10.1104/pp.010063

Feller, A., Machemer, K., Braun, E. L., \& Grotewold, E. (2011). Evolutionary and comparative analysis of MYB and bHLH plant transcription factors. Plant Journal, 66 (1), 94-116. https://doi.org/10.1111/j.1365313x.2010.04459.x

Feucht, W., Schmid, M., \& Treutter, D. (2014). Flavanols and flavonols in the nuclei of conifer genotypes with different growth. Forests, 5 (9), 2122-2135. https://doi.org/10.3390/f5092122

Field, K. J., Pressel, S., Duckett, J. G., Rimington, W. R., \& Bidartondo, M. I. (2015). Symbiotic options for the conquest of land.Trends in Ecology $\&$ Evolution, 30 (8), 477-486. https://doi.org/10.1016/j.tree.2015.05.007

Fini, A., Brunetti, C., Di Ferdinando, M., Ferrini, F., \& Tattini, M. (2011). Stress-induced flavonoid biosynthesis and the antioxidant machinery of plants. Plant Signaling $\&$ Behavior, 6 (5), 709-711. https://doi.org/10.4161/psb.6.5.15069

Firuzi, O., Mladenka, P. e., Petrucci, R., Marrosu, G., \& Saso, L. (2004). Hypochlorite scavenging activity of flavonoids. Journal of Pharmacy and Pharmacology, 56 (6), 801-807. https://doi.org/10.1211/0022357023556

Franco, D. M., Silva, E. M., Saldanha, L. L., Adachi, S. A., Schley, T. R., Rodrigues, T. M., .. Rolim de Almeida, L. F. (2015). Flavonoids modify root growth and modulate expression of SHORT-ROOT and HD-ZIP III.Journal of Plant Physiology, 188 , 89-95. https://doi.org/10.1016/j.jplph.2015.09.009

Friml, J., \& Jones, A. R. (2010). Endoplasmic reticulum: The rising compartment in auxin biology. Plant Physiology, 154 (2), 458-462. https://doi.org/10.1104/pp.110.161380 
Galway, M. E., Masucci, J. D., Lloyd, A. M., Walbot, V., Davis, R. W., \& Schiefelbein, J. W. (1994). The TTG gene is required to specify epidermal cell fate and cell patterning in the Arabidopsis root.Developmental Biology, 166 (2), 740-754. https://doi.org/10.1006/dbio.1994.1352

Gao, H. J., \& Yang, H. Q. (2011). Nitric oxide effect on root architecture development in Malus seedlings. Plant, Soil and Environment, 57 (No. 9), 418-422. https://doi.org/10.17221/209/2011-pse

Gayomba, S. R., Watkins, J. M., \& Muday, G. K. (2017). Flavonols regulate plant growth and development through regulation of auxin transport and cellular redox status. In Recent Advances in Polyphenol Research, Volume 5 (eds K. Yoshida, V. Cheynier, \& S. Quideau), pp. 143-170. John Wiley \& Sons, Chichester.

Gorniak, I., Bartoszewski, R., \& Kroliczewski, J. (2018). Comprehensive review of antimicrobial activities of plant flavonoids.Phytochemistry Reviews, 18 (1), 241-272. https://doi.org/10.1007/s11101-018-9591-z

Griep, M. A., Blood, S., Larson, M. A., Koepsell, S. A., \& Hinrichs, S. H. (2007). Myricetin inhibits Escherichia coli DNA B helicase but not primase. Bioorganic \& Medicinal Chemistry, 15 (22), 7203-7208. https://doi.org/10.1016/j.bmc.2007.07.057

Grunewald, W., De Smet, I., Lewis, D. R., Lofke, C., Jansen, L., Goeminne, G., ... Beeckman, T. (2012). Transcription factor WRKY23 assists auxin distribution patterns during Arabidopsis root development through local control on flavonol biosynthesis. Proceedings of the National Academy of Sciences of the United States of America, 109 (5), 1554-1559. https://doi.org/10.1073/pnas.1121134109

Haenen, G. R. M. M., Paquay, J. B. G., Korthouwer, R. E. M., \& Bast, A. (1997). Peroxynitrite scavenging by flavonoids. Biochemical and Biophysical Research Communications, 236 (3), 591-593. https://doi.org/10.1006/bbrc.1997.7016

Hartwig, U. A., Joseph, C. M., \& Phillips, D. A. (1991). Flavonoids released naturally from alfalfa seeds enhance growth rate ofRhizobium meliloti . Plant Physiology, 95 (3), 797-803. https://doi.org/10.1104/pp.95.3.797

Hassan, S., \& Mathesius, U. (2012). The role of flavonoids in root-rhizosphere signalling: Opportunities and challenges for improving plant-microbe interactions. Journal of Experimental Botany, 63 (9), 3429-3444. https://doi.org/10.1093/jxb/err430

Havsteen, B. (1983). Flavonoids, a class of natural products of high pharmacological potency. Biochemical Pharmacology, 32 (7), 1141-1148. https://doi.org/10.1016/0006-2952(83)90262-9

Hayes, S., Velanis, C. N., Jenkins, G. I., \& Franklin, K. A. (2014). UV-B detected by the UVR8 photoreceptor antagonizes auxin signaling and plant shade avoidance. Proceedings of the National Academy of Sciences of the United States of America, 111 (32), 11894-11899. https://doi.org/10.1073/pnas.1403052111

Hectors, K., van Oevelen, S., Guisez, Y., Prinsen, E., \& Jansen, M. A. K. (2012). The phytohormone auxin is a component of the regulatory system that controls UV-mediated accumulation of flavonoids and UV-induced morphogenesis. Physiologia Plantarum, 145 (4), 594-603. https://doi.org/10.1111/j.1399-3054.2012.01590.x

Hirayama, T., \& Shinozaki, K. (2007). Perception and transduction of abscisic acid signals: Keys to the function of the versatile plant hormone ABA. Trends in Plant Science, 12 (8), 343-351. https://doi.org/10.1016/j.tplants.2007.06.013

Imin, N., Nizamidin, M., Wu, T., \& Rolfe, B. G. (2007). Factors involved in root formation in Medicago truncatula. Journal of Experimental Botany, 58 (3), 439-451. https://doi.org/10.1093/jxb/erl224

Jammes, F., Song, C., Shin, D., Munemasa, S., Takeda, K., Gu, D., .. Kwak, J. M. (2009). MAP kinases MPK9 and MPK12 are preferentially expressed in guard cells and positively regulate ROS-mediated ABA signaling. Proceedings of the National Academy of Sciences of the United States of America, 106 (48), 20520-20525. https://doi.org/10.1073/pnas.0907205106 
Jansen, M. A. K. (2002). Ultraviolet-B radiation effects on plants: Induction of morphogenic responses. Physiologia Plantarum, 116 (3), 423-429. https://doi.org/10.1034/j.1399-3054.2002.1160319.x

Jorgensen, R. (1993). The origin of land plants: A union of alga and fungus advanced by flavonoids? Biosystems, 31 (2-3), 193-207. https://doi.org/10.1016/0303-2647(93)90049-i

Keilig, K., \& Ludwig-Muller, J. (2009). Effect of flavonoids on heavy metal tolerance in Arabidopsis thaliana seedlings.Botanical Studies, 50 , 311-318.

Kidd, P. S., Llugany, M., Poschenrieder, C., Gunse, B., \& Barcelo, J. (2001). The role of root exudates in aluminium resistance and silicon-induced amelioration of aluminium toxicity in three varieties of maize (Zea mays L.). Journal of Experimental Botany, 52 (359), 1339-1352. https://doi.org/10.1093/jexbot/52.359.1339

Kitamura, S. (2006). Transport of flavonoids: From cytosolic synthesis to vacuolar accumulation. In The Science of Flavonoids (ed E. Grotewold), pp. 123-146. Springer, New York.

Komis, G., Šamajová, O., Ovečka, M., \& Šamaj, J. (2018). Cell and developmental biology of plant mitogenactivated protein kinases. Annual Review of Plant Biology, 69 (1), 237-265. https://doi.org/10.1146/annurevarplant-042817-040314

Kovtun, Y., Chiu, W. L., Tena, G., \& Sheen, J. (2000). Functional analysis of oxidative stress-activated mitogen-activated protein kinase cascade in plants. Proceedings of the National Academy of Sciences of the United States of America, 97 (6), 2940-2945. https://doi.org/10.1073/pnas.97.6.2940

Kriechbaumer, V., Seo, H., Park, W. J., \& Hawes, C. (2015). Endoplasmic reticulum localization and activity of maize auxin biosynthetic enzymes. Journal of Experimental Botany, 66 (19), 6009-6020. https://doi.org/10.1093/jxb/erv314

Kuhn, B. M., Nodzyński, T., Errafi, S., Bucher, R., Gupta, S., Aryal, B., .. Ringli, C. (2017). Flavonolinduced changes in PIN2 polarity and auxin transport in the Arabidopsis thaliana rol1-2 mutant require phosphatase activity. Scientific Reports, 7 , 41906-41906. https://doi.org/10.1038/srep41906

Kumar, S., \& Pandey, A. K. (2013). Chemistry and biological activities of flavonoids: An overview. The Scientific World Journal, 2013, 162750-162750. https://doi.org/10.1155/2013/162750

Kurepa, J., Shull, T. E., \& Smalle, J. A. (2016). Quercetin feeding protects plants against oxidative stress. F1000Research, 5 , 2430. https://doi.org/10.12688/f1000research.9659.1

Kutchan, T. M., Gershenzon, J., Møller, B. L., \& Gang, D. R. (2015). Natural products. In Biochemistry 8 Molecular Biology of Plants, Second Edition (eds B. B. Buchanan, W. Gruissem, \& R. L. Jones), pp. 1132-1206. John Wiley \& Sons, Chichester.

Lakhanpal, P., \& Rai, D. K. (2007). Quercetin: A versatile flavonoid.Internet Journal of Medical Update, 2 (2), 20-35. https://doi.org/10.4314/ijmu.v2i2.39851

Lee, K. H., Piao, H. L., Kim, H.-Y., Choi, S. M., Jiang, F., Hartung, W., .. Hwang, I. (2006). Activation of glucosidase via stress-induced polymerization rapidly increases active pools of abscisic acid.Cell, 126 (6), 1109-1120. https://doi.org/10.1016/j.cell.2006.07.034

Leng, P., Yuan, B., \& Guo, Y. (2013). The role of abscisic acid in fruit ripening and responses to abiotic stress. Journal of Experimental Botany, 65 (16), 4577-4588. https://doi.org/10.1093/jxb/eru204

Lesjak, M., Beara, I., Simin, N., Pintać, D., Majkić, T., Bekvalac, K., .. Mimica-Dukić, N. (2018). Antioxidant and anti-inflammatory activities of quercetin and its derivatives. Journal of Functional Foods, 40 , 68-75. https://doi.org/10.1016/j.jff.2017.10.047

Lewis, D. R., Ramirez, M. V., Miller, N. D., Vallabhaneni, P., Ray, W. K., Helm, R. F., .. Muday, G. K. (2011). Auxin and ethylene induce flavonol accumulation through distinct transcriptional networks. Plant 
Physiology, 156 (1), 144-164. https://doi.org/10.1104/pp.111.172502

Li, Y., Kong, D., Fu, Y., Sussman, M. R., \& Wu, H. (2020). The effect of developmental and environmental factors on secondary metabolites in medicinal plants. Plant Physiology and Biochemistry, 148 , 80-89. https://doi.org/10.1016/j.plaphy.2020.01.006

Li, Y., Yao, J., Han, C., Yang, J., Chaudhry, M. T., Wang, S., .. Yin, Y. (2016). Quercetin, inflammation and immunity. Nutrients, 8 (3), 167-167. https://doi.org/10.3390/nu8030167

Magar, R. T., \& Sohng, J. K. (2020). A review on structure, modifications and structure-activity relation of quercetin and its derivatives. Journal of Microbiology and Biotechnology, 30 (1), 11-20. https://doi.org/10.4014/jmb.1907.07003

Mahajan, M., \& Yadav, S. K. (2013). Effect of quercetin and epicatechin on the transcript expression and activity of antioxidant enzymes in tobacco seedlings. American Journal of Biochemistry and Molecular Biology, 3 (1), 81-90. https://doi.org/10.3923/ajbmb.2013.81.90

Mathesius, U. (2001). Flavonoids induced in cells undergoing nodule organogenesis in white clover are regulators of auxin breakdown by peroxidase. Journal of Experimental Botany, 52 (Suppl. 1), 419-426. https://doi.org/10.1093/jexbot/52.suppl_1.419

Metodiewa, D., Jaiswal, A. K., Cenas, N., Dickancaité, E., \& Segura-Aguilar, J. (1999). Quercetin may act as a cytotoxic prooxidant after its metabolic activation to semiquinone and quinoidal product.Free Radical Biology and Medicine, 26 (1-2), 107-116. https://doi.org/10.1016/s0891-5849(98)00167-1

Michniewicz, M., Zago, M. K., Abas, L., Weijers, D., Schweighofer, A., Meskiene, I., .. Friml, J. (2007). Antagonistic regulation of PIN phosphorylation by PP2A and PINOID directs auxin flux. Cell, 130 (6), 1044-1056. https://doi.org/10.1016/j.cell.2007.07.033

Mierziak, J., Kostyn, K., \& Kulma, A. (2014). Flavonoids as important molecules of plant interactions with the environment. Molecules, 19 (10), 16240-16265. https://doi.org/10.3390/molecules191016240

Mishra, B., Priyadarsini, K. I., Kumar, M. S., Unnikrishnan, M. K., \& Mohan, H. (2003). Effect of $O$ glycosilation on the antioxidant activity and free radical reactions of a plant flavonoid, chrysoeriol.Bioorganic \& Medicinal Chemistry, 11 (13), 2677-2685. https://doi.org/10.1016/s0968-0896(03)00232-3

Mo, Y., Nagel, C., \& Taylor, L. P. (1992). Biochemical complementation of chalcone synthase mutants defines a role for flavonols in functional pollen. Proceedings of the National Academy of Sciences of the United States of America, 89 (15), 7213-7217. https://doi.org/10.1073/pnas.89.15.7213

Moreland, D. E., \& Novitzky, W. P. (1987). Interference by luteolin, quercetin, and taxifolin with chloroplast-mediated electron transport and phosphorylation. Plant and Soil, 98 (1), 145-159. https://doi.org/10.1007/bf02381735

Mravec, J., Skůpa, P., Bailly, A., Hoyerová, K., Křeček, P., Bielach, A., .. Friml, J. (2009). Subcellular homeostasis of phytohormone auxin is mediated by the ER-localized PIN5 transporter. Nature, 459 (7250), 1136-1140. https://doi.org/10.1038/nature08066

Nabavi, S. M., Šamec, D., Tomczyk, M., Milella, L., Russo, D., Habtemariam, S., ... Shirooie, S. (2020). Flavonoid biosynthetic pathways in plants: Versatile targets for metabolic engineering.Biotechnology Advances, 38 , 107316. https://doi.org/10.1016/j.biotechadv.2018.11.005

Neuffer, M. G., Coe, E. H., \& Wessler, S. R. (1997). Mutants of Maize . New York: Cold Spring Harbor Laboratory Press.

Ng, J. L. P., Hassan, S., Truong, T. T., Hocart, C. H., Laffont, C., Frugier, F., \& Mathesius, U. (2015). Flavonoids and auxin transport inhibitors rescue symbiotic nodulation in the Medicago truncatulacytokinin perception mutant cre1. Plant Cell, 27 (8), 2210-2226. https://doi.org/10.1105/tpc.15.00231 
Ohemeng, K. A., Schwender, C. F., Fu, K. P., \& Barrett, J. F. (1993). DNA gyrase inhibitory and antibacterial activity of some flavones(1).Bioorganic 83 Medicinal Chemistry Letters, 3 (2), 225-230. https://doi.org/10.1016/s0960-894x(01)80881-7

Ono, K., Nakane, H., Fukushima, M., Chermann, J.-C., \& Barre-Sinoussi, F. (1990). Differential inhibitory effects of various flavonoids on the activities of reverse transcriptase and cellular DNA and RNA polymerases. European Journal of Biochemistry, 190 (3), 469-476. https://doi.org/10.1111/j.1432-1033.1990.tb15597.x

Pan, Q.-H., Li, M.-J., Peng, C.-C., Zhang, N., Zou, X., Zou, K.-Q., .. Z Zhang, D.-P. (2005). Abscisic acid activates acid invertases in developing grape berry. Physiologia Plantarum, 125 (2), 157-170. https://doi.org/10.1111/j.1399-3054.2005.00552.x

Parvin, K., Hasanuzzaman, M., Bhuyan, M. H. M. B., Mohsin, S. M., Fujita, \& Masayuki. (2019). Quercetin mediated salt tolerance in tomato through the enhancement of plant antioxidant defense and glyoxalase systems. Plants, 8 (8), 247. https://doi.org/10.3390/plants8080247

Peer, W. A., Blakeslee, J. J., Yang, H., \& Murphy, A. S. (2011). Seven things we think we know about auxin transport. Molecular Plant, 4 (3), 487-504. https://doi.org/10.1093/mp/ssr034

Peer, W. A., Cheng, Y., \& Murphy, A. S. (2013). Evidence of oxidative attenuation of auxin signalling. Journal of Experimental Botany, 64 (9), 2629-2639. https://doi.org/10.1093/jxb/ert152

Peer, W. A., \& Murphy, A. S. (2006). Flavonoids as signal molecules: Targets of flavonoid action. In The Science of Flavonoids (ed E. Grotewold), pp. 239-268. Springer, New York, NY.

Peer, W. A., \& Murphy, A. S. (2007). Flavonoids and auxin transport: Modulators or regulators? Trends in Plant Science, 12 (12), 556-563. https://doi.org/10.1016/j.tplants.2007.10.003

Petroni, K., \& Tonelli, C. (2011). Recent advances on the regulation of anthocyanin synthesis in reproductive organs. Plant Science, 181 (3), 219-229. https://doi.org/10.1016/j.plantsci.2011.05.009

Pires, N., \& Dolan, L. (2010). Origin and diversification of basic-helix-loop-helix proteins in plants. Molecular Biology and Evolution, 27 (4), 862-874. https://doi.org/10.1093/molbev/msp288

Plaper, A., Golob, M., Hafner, I., Oblak, M., Šolmajer, T., \& Jerala, R. (2003). Characterization of quercetin binding site on DNA gyrase.Biochemical and Biophysical Research Communications, 306 (2), 530-536. https://doi.org/10.1016/s0006-291x(03)01006-4

Pollastri, S., \& Tattini, M. (2011). Flavonols: Old compounds for old roles. Annals of Botany, 108 (7), 1225-1233. https://doi.org/10.1093/aob/mcr234

Potters, G., Pasternak, T. P., Guisez, Y., \& Jansen, M. A. K. (2009). Different stresses, similar morphogenic responses: Integrating a plethora of pathways. Plant, Cell \&3 Environment, 32 (2), 158-169. https://doi.org/10.1111/j.1365-3040.2008.01908.x

Potters, G., Pasternak, T. P., Guisez, Y., Palme, K. J., \& Jansen, M. A. K. (2007). Stressinduced morphogenic responses: Growing out of trouble? Trends in Plant Science, 12 (3), 98-105. https://doi.org/10.1016/j.tplants.2007.01.004

Prado, D., Dionizio, R. C., Vianello, F., Baratella, D., Costa, S., \& Lima, G. (2015). Quercetin and indole 3-butyric acid (IBA) as rooting inducers in Eucalyptus grandis $\times$ E. urophylla. Australian Journal of Crop Science, 9 , 1057-1063.

Ratty, A. K., \& Das, N. P. (1988). Effects of flavonoids on nonenzymatic lipid peroxidation: Structure-activity relationship.Biochemical Medicine and Metabolic Biology, 39 (1), 69-79. https://doi.org/10.1016/08854505(88)90060-6

Reddy, A. M., Reddy, V. S., Scheffler, B. E., Wienand, U., \& Reddy, A. R. (2007). Novel transgenic rice overexpressing anthocyanidin synthase accumulates a mixture of flavonoids leading to an increased antioxidant 
potential. Metabolic Engineering, 9 (1), 95-111. https://doi.org/10.1016/j.ymben.2006.09.003

Rice-Evans, C. A., Miller, N. J., \& Paganga, G. (1996). Structure-antioxidant activity relationships of flavonoids and phenolic acids. Free Radical Biology and Medicine, 20 (7), 933-956. https://doi.org/10.1016/08915849(95)02227-9

Ryan, K. G., Swinny, E. E., Markham, K. R., \& Winefield, C. (2002). Flavonoid gene expression and UV photoprotection in transgenic and mutant Petunia leaves. Phytochemistry, 59 (1), 23-32. https://doi.org/10.1016/s0031-9422(01)00404-6

Sanchita, A. S. (2018). Gene expression analysis in medicinal plants under abiotic stress conditions. In Plant Metabolites and Regulation Under Environmental Stress (eds P. Ahmad, M. A. Ahanger, V. Singh, D. K. Tripathi, P. Alam, \& M. N. Alyemeni), pp. 407-414. Academic Press, London.

Santelia, D., Henrichs, S., Vincenzetti, V., Sauer, M., Bigler, L., Klein, M., ... Martinoia, E. (2008). Flavonoids redirect PIN-mediated polar auxin fluxes during root gravitropic responses. Journal of Biological Chemistry, 283 (45), 31218-31226. https://doi.org/10.1074/jbc.M710122200

Santos, A. C., Uyemura, S. A., Lopes, J. L. C., Bazon, J. N., Mingatto, F. E., \& Curti, C. (1998). Effect of naturally occurring flavonoids on lipid peroxidation and membrane permeability transition in mitochondria.Free Radical Biology and Medicine, 24 (9), 1455-1461. https://doi.org/10.1016/s0891-5849(98)00003-3

Simon, S., Skůpa, P., Viaene, T., Zwiewka, M., Tejos, R., Klíma, P., .. Friml, J. (2016). PIN6 auxin transporter at endoplasmic reticulum and plasma membrane mediates auxin homeostasis and organogenesis inArabidopsis . New Phytologist, 211 (1), 65-74. https://doi.org/10.1111/nph.14019

Stafford, H. A. (1991). Flavonoid evolution: An enzymic approach.Plant Physiology, 96 (3), 680-685. https://doi.org/10.1104/pp.96.3.680

Stracke, R., Favory, J.-J., Gruber, H., Bartelniewoehner, L., Bartels, S., Binkert, M., .. Ulm, R. (2010). The Arabidopsis bZIP transcription factor HY5 regulates expression of the PFG1/MYB12 gene in response to light and ultraviolet-B radiation. Plant, Cell \& Environment, 33 , 88-103. https://doi.org/10.1111/j.13653040.2009.02061.x

Stracke, R., Ishihara, H., Huep, G., Barsch, A., Mehrtens, F., Niehaus, K., \& Weisshaar, B. (2007). Differential regulation of closely related R2R3-MYB transcription factors controls flavonol accumulation in different parts of the Arabidopsis thaliana seedling. Plant Journal, 50 (4), 660-677. https://doi.org/10.1111/j.1365313X.2007.03078.x

Sugiyama, A., Shitan, N., \& Yazaki, K. (2007). Involvement of a soybean ATP-binding cassette-type transporter in the secretion of genistein, a signal flavonoid in legume-Rhizobium symbiosis. Plant Physiology, 144 (4), 2000-2008. https://doi.org/10.1104/pp.107.096727

Sun, C., Fu, J., Chen, J., Jiang, L., \& Pan, Y. (2010). On-line HPLC method for screening of antioxidants against superoxide anion radical from complex mixtures. Journal of Separation Science, 33 , 1018-1023. https://doi.org/10.1002/jssc.200900588

Suriyanarayanan, B., Shanmugam, K., \& Santhosh, R. S. (2013). Synthetic quercetin inhibits mycobacterial growth possibly by interacting with DNA gyrase. Romanian Biotechnological Letters, 18 (5), 8587-8593.

Takahama, U. (1984). Quercetin by carotenoid radical generated in illuminated spinach chloroplasts: The effect of ascorbate on quercetin oxidation. Plant and Cell Physiology, 25 (7), 1181-1185. https://doi.org/10.1093/oxfordjournals.pcp.a076825

Takahashi, L., Sert, M. A., Kelmer-Bracht, A. M., Bracht, A., \& Ishii-Iwamoto, E. L. (1998). Effects of rutin and quercetin on mitochondrial metabolism and on ATP levels in germinating tissues of Glycine max . Plant Physiology and Biochemistry, 36 (7), 495-501. https://doi.org/10.1016/s0981-9428(98)80174-5 
Tanigawa, S., Fujii, M., \& Hou, D. (2007). Action of Nrf2 and Keap1 in ARE-mediated NQO1 expression by quercetin. Free Radical Biology and Medicine, 42 (11), 1690-1703. https://doi.org/10.1016/j.freeradbiomed.2007.02.017

Tattini, M., Gravano, E., Pinelli, P., Mulinacci, N., \& Romani, A. (2000). Flavonoids accumulate in leaves and glandular trichomes of Phillyrea latifolia exposed to excess solar radiation. New Phytologist, 148 (1), 69-77. https://doi.org/10.1046/j.1469-8137.2000.00743.x

Tattini, M., Sebastiani, F., Brunetti, C., Fini, A., Torre, S., Gori, A., ... Guidi, L. (2017). Dissecting molecular and physiological response mechanisms to high solar radiation in cyanic and acyanic leaves: A case study on red and green basil. Journal of Experimental Botany, 68 (9), 2425-2437. https://doi.org/10.1093/jxb/erx123

Tohge, T., \& Fernie, Alisdair R. (2016). Specialized metabolites of the flavonol class mediate root phototropism and growth. Molecular Plant, 9 (12), 1554-1555. https://doi.org/10.1016/j.molp.2016.10.019

Tossi, V., Cassia, R., Bruzzone, S., Zocchi, E., \& Lamattina, L. (2012). ABA says NO to UV-B: A universal response? Trends in Plant Science, 17 (9), 510-517. https://doi.org/10.1016/j.tplants.2012.05.007

Tossi, V., Lamattina, L., \& Cassia, R. (2009). An increase in the concentration of abscisic acid is critical for nitric oxide-mediated plant adaptive responses to UV-B irradiation. New Phytologist, 181 (4), 871-879. https://doi.org/10.1111/j.1469-8137.2008.02722.x

Tossi, V., Lamattina, L., Jenkins, G. I., \& Cassia, R. O. (2014). Ultraviolet-B-induced stomatal closure in Arabidopsis is regulated by the UV RESISTANCE LOCUS8 photoreceptor in a nitric oxide-dependent mechanism. Plant Physiology, 164 (4), 2220-2230. https://doi.org/10.1104/pp.113.231753

Van Acker, S. A. B. E., Van Den Berg, D.-j., Tromp, M. N. J. L., Griffioen, D. H., Van Bennekom, W. P., Van Der Vijgh, W. J. F., \& Bast, A. (1996). Structural aspects of antioxidant activity of flavonoids. Free Radical Biology and Medicine, 20 (3), 331-342. https://doi.org/10.1016/0891-5849(95)02047-0

Viaene, T., Landberg, K., Thelander, M., Medvecka, E., Pederson, E., Feraru, E., ... Friml, J. (2014). Directional auxin transport mechanisms in early diverging land plants. Current Biology, 24 (23), 2786-2791. https://doi.org/10.1016/j.cub.2014.09.056

Wagner, A. (2011). The molecular origins of evolutionary innovations. Trends in Genetics, 27 (10), 397-410. https://doi.org/10.1016/j.tig.2011.06.002

Wang, F., Wu, N., Zhang, L., Ahammed, G. J., Chen, X., Xiang, X., ... Zhou, Y. (2018). Light signalingdependent regulation of photoinhibition and photoprotection in tomato. Plant Physiology, 176 (2), 13111326. https://doi.org/10.1104/pp.17.01143

Wang, P., \& Song, C.-P. (2008). Guard-cell signalling for hydrogen peroxide and abscisic acid. New Phytologist, 178 (4), 703-718. https://doi.org/10.1111/j.1469-8137.2008.02431.x

Wasson, A. P., Pellerone, F. I., \& Mathesius, U. (2006). Silencing the flavonoid pathway in Medicago truncatula inhibits root nodule formation and prevents auxin transport regulation by rhizobia.Plant Cell, 18 (7), 1617-1629. https://doi.org/10.1105/tpc.105.038232

Watkins, J. M., Chapman, J. M., \& Muday, G. K. (2017). Abscisic acid-induced reactive oxygen species are modulated by flavonols to control stomata aperture. Plant Physiology, 175 (4), 1807-1825. https://doi.org/10.1104/pp.17.01010

Watkins, J. M., Hechler, P. J., \& Muday, G. K. (2014). Ethylene-induced flavonol accumulation in guard cells suppresses reactive oxygen species and moderates stomatal aperture. Plant Physiology, 164 (4), 1707-1717. https://doi.org/10.1104/pp.113.233528

Winkel-Shirley, B. (2001). Flavonoid biosynthesis. A colorful model for genetics, biochemistry, cell biology, and biotechnology. Plant Physiology, 126 (2), 485-493. https://doi.org/10.1104/pp.126.2.485 
Wolf, L., Rizzini, L., Stracke, R., Ulm, R., \& Rensing, S. A. (2010). The molecular and physiological responses of Physcomitrella patens to ultraviolet-B radiation. Plant Physiology, 153 (3), 1123-1134. https://doi.org/10.1104/pp.110.154658

Woodward, A. W., \& Bartel, B. (2005). Auxin: Regulation, action, and interaction. Annals of Botany, 95 (5), 707-735. https://doi.org/10.1093/aob/mci083

Wu, T., Zang, X., He, M., Pan, S., \& Xu, X. (2013). Structure-activity relationship of flavonoids on their anti-Escherichia coliactivity and inhibition of DNA gyrase. Journal of Agricultural and Food Chemistry, 61 (34), 8185-8190. https://doi.org/10.1021/jf402222v

Xu, H.-X., \& Lee, S. F. (2001). Activity of plant flavonoids against antibiotic-resistant bacteria. Phytotherapy Research, 15 (1), 39-43. https://doi.org/10.1002/1099-1573(200102)15:1<39::aid-ptr684>3.0.co;2-r

Xue, B., Charest, P. J., Devantier, Y., \& Rutledge, R. G. (2003). Characterization of a MYBR2R3 gene from black spruce (Picea mariana) that shares functional conservation with maize C1.Molecular Genetics and Genomics, 270 (1), 78-86. https://doi.org/10.1007/s00438-003-0898-z

Ylstra, B., Touraev, A., Moreno, R. M., Stöger, E., van Tunen, A. J., Vicente, O., ... Heberle-Bors, E. (1992). Flavonols stimulate development, germination, and tube growth of tobacco pollen. Plant Physiology, 100 (2), 902-907. https://doi.org/10.1104/pp.100.2.902

Yuan, R., Kender, W., \& Burns, J. (2003). Young fruit and auxin transport inhibitors affect the response of mature 'Valencia' oranges to abscission materials via changing endogenous plant hormones. Journal of the American Society for Horticultural Science, 128 (3), 302-308. https://doi.org/10.21273/JASHS.128.3.0302

Zhang, J., \& Peer, W. A. (2017). Auxin homeostasis: the DAO of catabolism. Journal of Experimental Botany, 68 (12), 3145-3154. https://doi.org/10.1093/jxb/erx221 


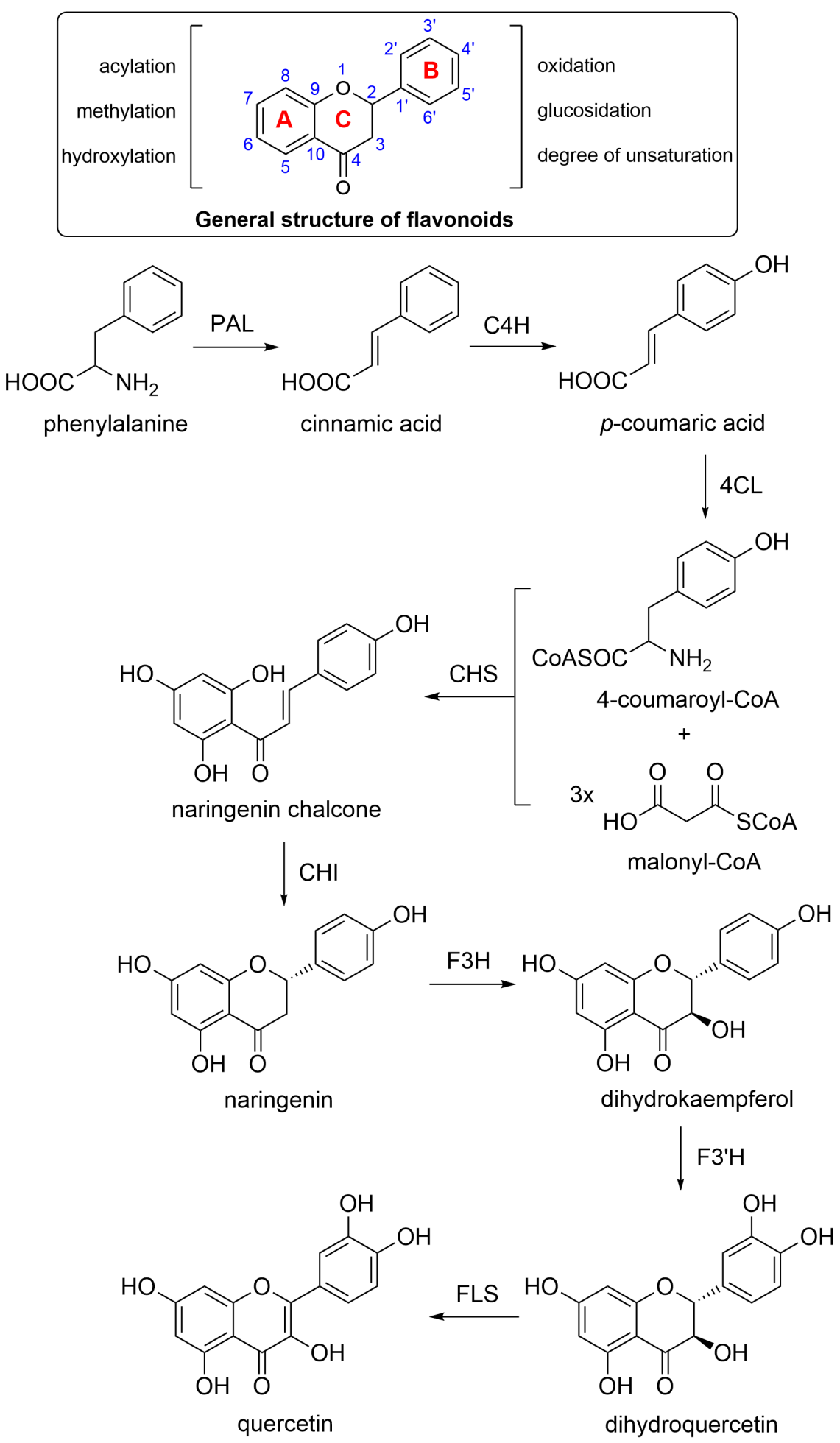




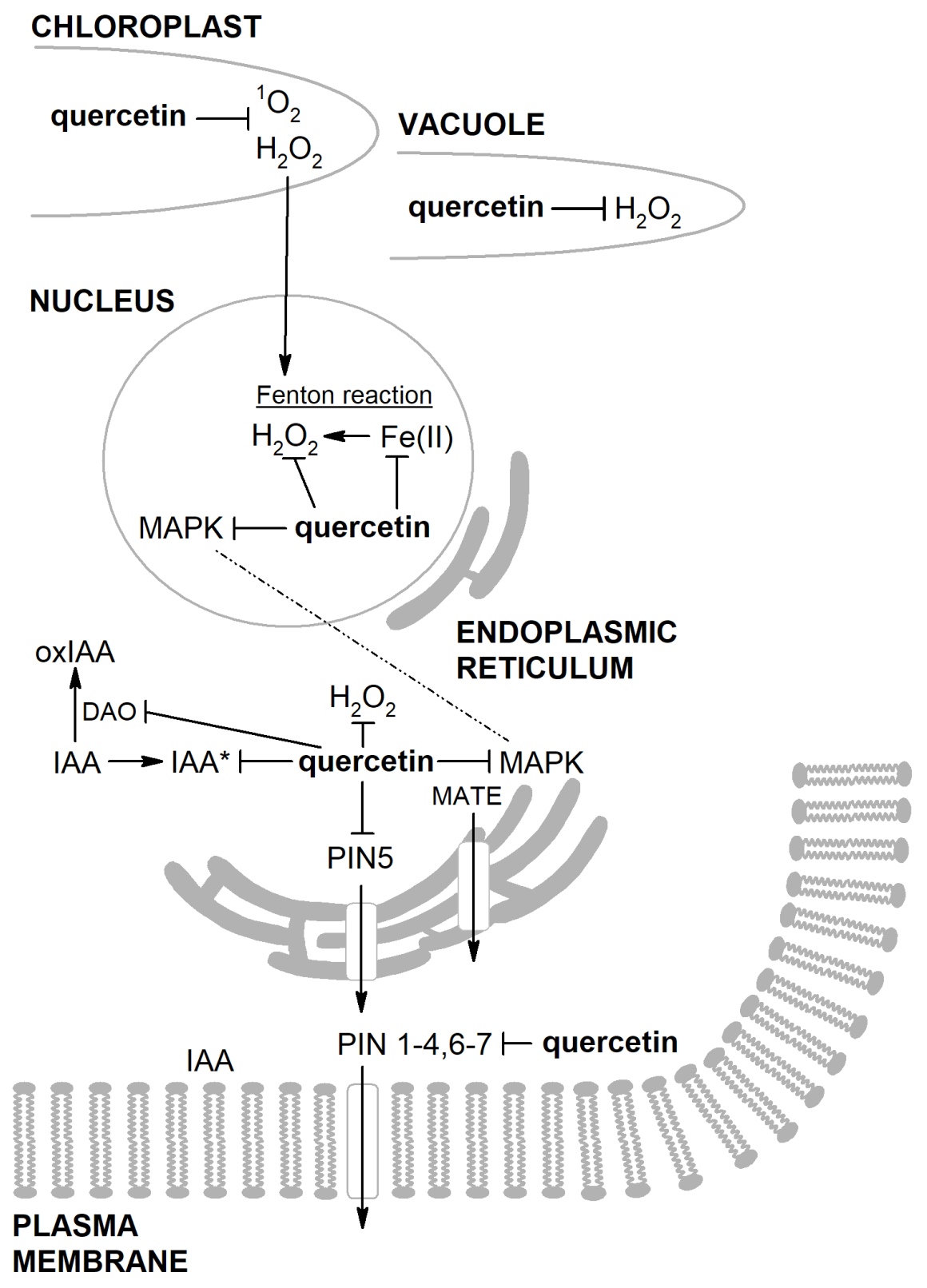




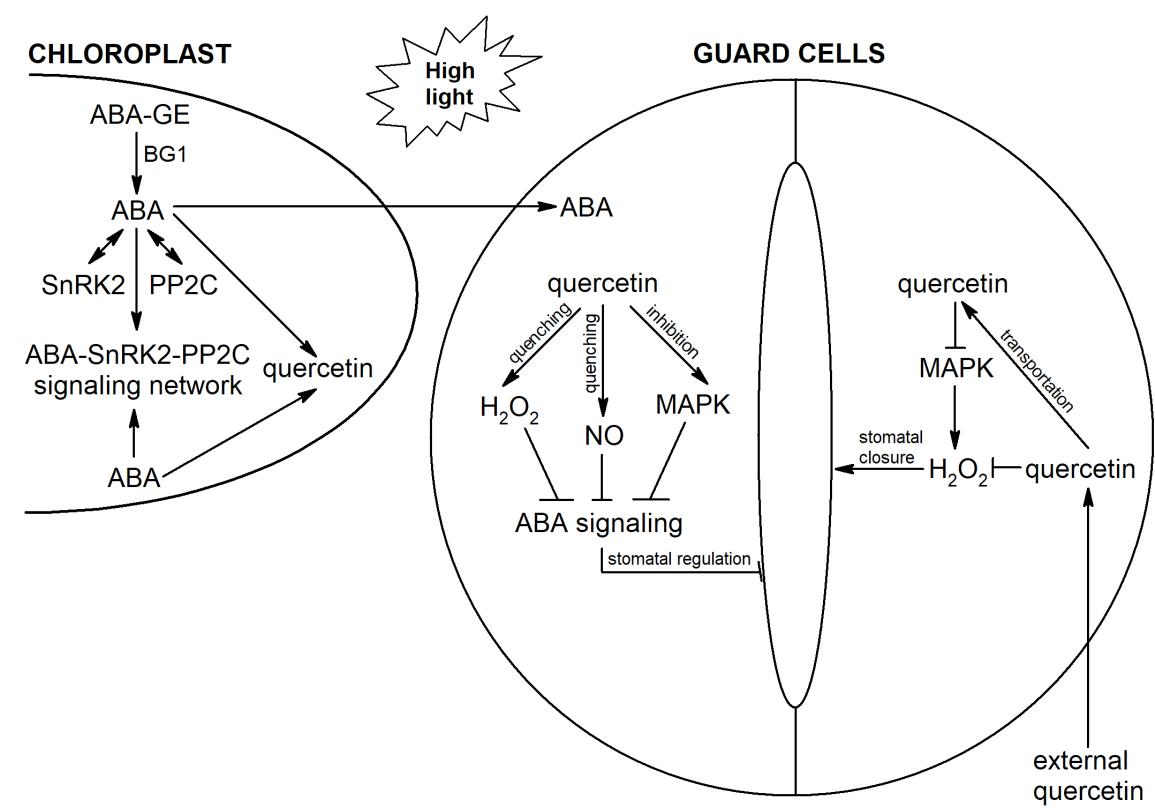

